\title{
A new constitutive equation on ice materials
}

\author{
Serdar Turgut Ince ${ }^{1,2,3}$, Ankush Kumar ${ }^{1,2}$ and Jeom Kee Paik ${ }^{* 1,2,4}$ \\ ${ }^{1}$ Department of Naval Architecture and Ocean Engineering, Pusan National University, \\ Busan 46241, Korea \\ ${ }^{2}$ The Korea Ship and Offshore Research Institute (The Lloyd's Register Foundation \\ Research Centre of Excellence), Pusan National University, Busan 46241, Korea \\ ${ }^{3}$ Department of Naval Architecture and Marine Engineering, Yildiz Technical University, \\ Istanbul 34349, Turkey \\ ${ }^{4}$ Department of Mechanical Engineering, University College London, London WC1E \\ 7JE, UK \\ * Corresponding author. Email: jeompaik@ pusan.ac.kr
}

\begin{abstract}
The structural crashworthiness analysis involving buckling, plasticity, crushing, and fracture with the strain-rate effects is required to evaluate the characteristics of structural deformations and impact energy dissipation at the event of collisions between ships or offshore platforms and icebergs. The constitutive equations of both steels and ice materials should be characterised for numerical computations as the collision impact energy is dissipated by the two colliding and deformable bodies, namely not only ships or offshore platforms but also icebergs. The primary objective of the present study is to examine ice properties and propose a constitutive equation of ice materials which shall be implemented into nonlinear finite element method computations of the structural crashworthiness associated with the collisions. Previous studies are first surveyed in tems of the influencing parameters as the many uncertainties involved make the problem highly complex. The parameters affecting the mechanical properties of ice materials are then discussed. In addition to referencing the existing test database associated with the mechanical properties of ice materials, a new test database is obtained by laboratory testing of the authors' group. Based on findings from the existing and the new test database, a new constitutive equation used for ice materials is proposed associated with quasi-static and impact responses.
\end{abstract}

Keywords: Constitutive equation on ice materials, Johnson-Cook constitutive equation, ice material, structural crashworthiness, impact

\section{Introduction}

Water, the source of life, appears in both its liquid and solid forms. Ice has a unique structure, but it is considered as a class of materials rather than a single specific material (Shazly et al. 2009). Ice is an important element that affects cold ocean exploration, polar marine transportation and the design of ships and offshore structures that operate in arctic areas.

It has grown increasingly important to understand ice as offshore exploitation for oil and natural gas has increased in arctic areas. Engineers face numerous challenges in dealing with the forces exerted on structures that operate in ice-infested waters. Estimating ice loads is necessary, not only for calculating deformations on a ship's structure but also for assessing the minimum power level of a ship's main engine and its manoeuvrability. Furthermore, predicting ice loads is essential in designing icebreakers. 
Analytical techniques, numerical methods, or small- and full-scale experiments were used to estimate ice loads.

Ice-steel interaction may be assumed that both ice and steel are rigid, or that steel alone is rigid or vice versa. For better and more realistic results, both of these materials should be considered to be deformable. A considerable amount of research has been done to measure ice properties, and several review articles have been presented to summarise their findings (Timco \& Frederking 1996; Schulson 2001; Jones 2007). However, calculating ice behaviour remains a challenge for engineers, especially in terms of numerical methods. Previously, studies examining the forces of ice impact on ship hulls have used material models from specific experiments or have obtained their results by trial and error (Zamankhan 2010; Lau et al. 2011; Liu et al. 2011a; Zong 2012; Gagnon \& Wang 2012). Clearly, greater knowledge of the structural behaviour and material properties of ice is requiredto calculate interaction forces more accurately so that a greater number of realistic simulations can be analysed. Therefore, the old experiment database collections are extended with new literature and experiments, and regulated based on certain parameters in this study.

It is interesting to mention that the current industry practices in the nonlinear finite element method analysis of the steel structural crashworthiness involving plasticity and impact mechanics are to directly implement quasi-static tensile test database on the test specimen of steel materials associated with different types (e.g., mild steel or high tensile steel) or grades (e.g., grade A, D or E) in terms of true stress-true strain relationship and then to apply relevant models for strain rates (e.g., Cowper-Symonds equation) and fracture criteria. Ideally, the same approach must be applied for ice materials in association with different site-specific and season-specific metocean characteristics due to temperature, salinity and strain rates, among others, but it is extremely challenging to obtain the test database of ice materials even for quasi-static conditions. It is thus highly demanding to develop a relevant constitutive equation of ice materials.

The primary objective of the present study is to review literature in terms of the influencing parameters which highly affect mechanical properties of ice and to formulate a constitutive equation of ice materials that shall be implemented into nonlinear finite element method computations of the structural crashworthiness at the event of collisions between ships or offshore platforms and icebergs. As the characteristics of ice materials depend on site-specific and season-specific conditions, the constitutive equation and related strength model of ice materials is formulated as a function of influencing parameters where the related coefficients can be defined based on site-specific ice properties that correlate with metocean properties.

\section{Literature Review}

In this section, numerous articles are reviewed in terms of the properties of ice at material and structural levels, including its elastic behaviour and its uniaxial compressive strength in association with impact loading speed and to various metocean conditions. Nnumerical ice models are also examined.

\subsection{The behaviour of ice at material and structural levels}

In nature, ice is a very complex material, with many differing crystalline structures and a wide diversity of physical and mechanical properties. The strength of ice depends on various factors, including temperature, crystalline structure, salinity, and loading conditions. For instance, bending tests have found that the structural strength of ice differs 
from that of materials having purely uniaxial tensile strength (Hawkes \& Mellor 1972). Sea ice has additional parameters that affect its properties, such as salinity, density and grain size. Sea ice grows in thin layers, and as it freezes it incorporates liquid brine and air bubbles(Cole 1998).

Ice displays two kinds of inelastic behaviour under compression. It is ductile at lower rates of deformation and brittle at higher rates and transition of ductile to brittle occures at certain strain rate. Various studies have focused on explaining ice behaviour and the strain-rate relationship (Schulson 2001; Petrovic 2003; Moslet 2007; Shazly et al. 2009). Additionally, this change is seen clearly during the experiments of this study. Jones (2007) suggested a number of equations to estimate the strain-rate effect on the compressive strength of freshwater and iceberg ice, based on results from both the literature and his own experiments. Other researchers have focused on the temperature effect (Arakawa \& Maeno 1997; Sammonds et al. 1998). However, a more inclusive material model is needed to characterise the ice behaviour.

\subsection{Ice models for numerical computations}

With advances in the capacity of computers and computing techniques, engineers are able of doing increasingly complicated simulations of the behaviour at material and structural levels. This capability of technology gives us the freedom to focus our intelligence to define the material properties of ice, and to use macros and other tools to modify designs in conjunction with specific requirements.

Three approaches are commonly used for the numerical simulation of ice and steel interaction: strength design, ductile design and shared energy design (Liu et al. 2011b; Norsok 2013). As for steel, numerous studies have been done and many material models are available to numerically simulate steel's behaviour. For simulating ice behaviour, researchers have used various material model approaches, including crushable foam modelling, the Lemaitre damage model, or the smoothed particle hydrodynamic (SPH) model. However, none of these material models considers all of the factors that affect the mechanical behaviour of ice.

Gagnon (2011) used a crushable foam material model and defined two stress curves: yield stress versus volumetric strain. This model was able to solve problems in which the top layer of ice was melting and the lower layers of ice remained solid. Figure 1 illustrates the stress-strain relations as discerned by Gagnon. The low-stress curve is for crushed ice and the high-stress curve is for the solid layer of ice. The outer ice and inner ice temperatures can differ because the surrounding water may vary from a minimum of $-2^{\circ} \mathrm{C}$ to higher temperatures. As already mentioned, changes in temperature greatly affect ice strength. Therefore, if two ice layers have different temperatures, it is more realistic to make two different ice material definitions. 


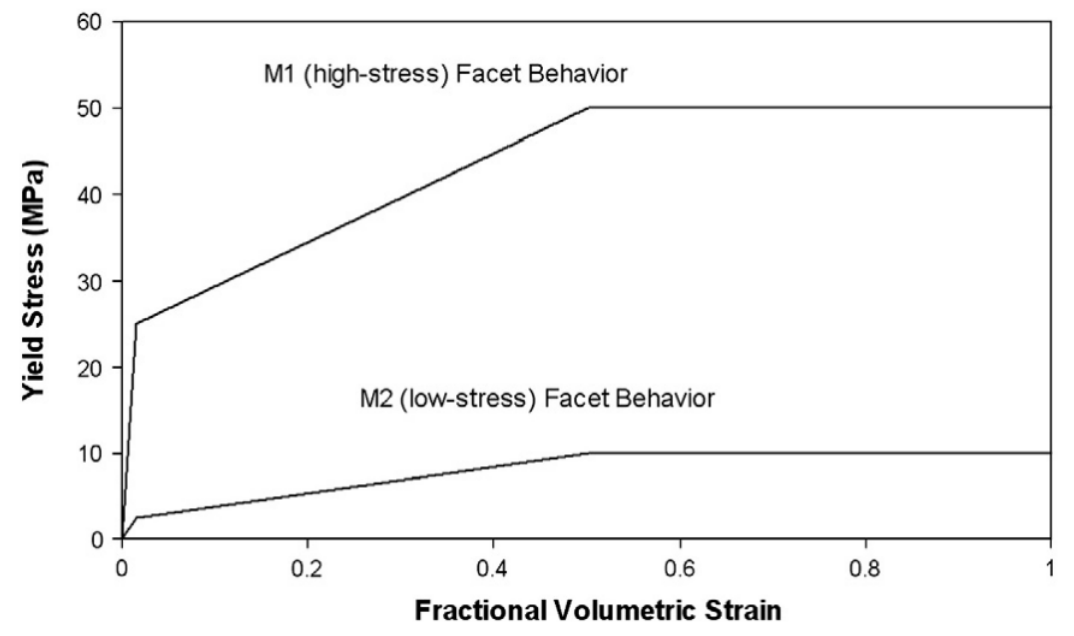

Figure 1. Stress versus volumetric strain curves for the high-stress and low-stress crushable foam facets as investigated by Gagnon (2011).

von Bock und Polach and Ehlers (2013) used randomly created air and liquid elements along with the Lemaitre damage model (Lemaitre \& Desmorat 2015). For liquid particles, they used elastic fluid material (4.5\%), and the air element (1\%) was deleted. The Lemaitre damage model showed pressure independent plasticity material behaviour. Damage was represented as progressive weakening of the grain boundaries.

The SPH (smoothed particle hydrodynamics) model is a computational method used for simulating fluid flows. This method has been used for numeric solutions to problems in many fields of engineering such as astrophysics, ballistics or oceanography. SPH is a meshless method. Ortiz et al. (2015) used a solid SPH model to predict the dynamic crushing behaviour of ice.

Liu et al. (2011b) used a simple plastic model that was based on plastic theory and was strain rate dependent. They combined the Tsai $\mathrm{Wu}$ yield surface criteria and the associated flow rule to better describe ice behaviour. These researchers were the first to use the Tsai $\mathrm{Wu}$ yield criteria for an FEM application in iceberg simulation. Liu et al. also proposed a quasi-static model to simulate ice structural behaviour. In addition, the HolmquistJohnson-Cook model and the brittle damage model have been used for modelling ice behaviour numerically (Nisja 2014).

The main challenge for researchers in this area is to simulate the behaviour of ice in a way that accounts for the complexity of ice fractures and the varieties of ice behaviour under changing conditions.

\section{Parameters Affecting the Mechanical Properties of Ice Material}

Ice is a crystalline material, and its structure includes a mixture of ice grains and varying volumes of brine. Ice grained formation requires a stress at least 60 times greater than that of the ice structure composition (Duval et al. 1983). Ice structure characteristics depend on environmental conditions such as daily/seasonal temperatures, winds, waves and seawater ingredients. Thus, ice contains differently orientated crystals, and most saline ice is contained between the crystals. Therefore, the material properties of ice and its structural properties are not the same.

Although the material properties of ice are more stable than its structural properties, a slight misorientation between the crystals can make ice behave differently from uniformly oriented ice. Also, it is nearly inconceivable to find fully oriented ice in nature. Ice grains are very small and their sizes and shapes are not constant, so particular grains 
cannot be used to determine the mesh size for numerical models. Hence, focusing on the structural behaviour of ice is more practical than focusing on its material behaviour.

Examining elastic and failure strength behaviour may help us to better understand the structural behaviour of ice. However, these kinds of behaviour cannot be explained in the classic way, because ice exhibits too complex mechanism to deal with. A number of parameters affect the structural behaviour of ice, such as temperature, strain rate, salinity, minerals, porosity and density. To examine ice strength and fracture mechanism, the parameters are focused on the greatest effect, namely impact speed and environmental factors. Table 1 summarises the highly influencing parameters which were investigated in this study.

Table 1 Most influencing parameters of ice mechanical behaviour

\begin{tabular}{|l|l|}
\hline Parameter & Description \\
\hline Temperature & $\begin{array}{l}\text { Decrement temperature increases strength and low } \\
\text { temperature cause recrystalization during impact }\end{array}$ \\
\hline Salinity & $\begin{array}{l}\text { During freezing, it creates brine volumes which is weaker } \\
\text { layers between crystals }\end{array}$ \\
\hline Strain rate & It changes behaviour from ductile to brittle \\
\hline
\end{tabular}

\subsection{Metocean effect on ice properties}

The term 'metocean' comes from an abbreviation of the words 'meteorology' and 'oceanography'. This term is used in the offshore oil \& gas industry to describe the environment around an offshore structure. Metocean data are essential for the design of ships and offshore structures that are destined for ice-infested seas. Due to these environmental conditions, the properties of ice in different seas can differ greatly. For example, ice formation in arctic areas is very different from that of ice that forms on inland seas (Pashin et al. 2011). Thus, ice types are as diverse as the regions in which they form. The earth's cold regions have huge variations in their geography, resources and environmental conditions, and these different conditions create a variety of highly complex ice structures. The design of these structures requires practical knowledge of the physical changes in ice that occur throughout the year, depending on the current, wind, water ingredient, temperature, salinity, etc. In impact engineering (Jones 2012), it is necessary to simplify this complexity and to find reasonable solutions for ice behaviour. To accomplish this, we start by reviewing the properties of sea ice based on its temperature and salinity.

\subsubsection{Temperature effect}

Mechanical properties of all materials are affected by temperature. The effect of variations of temperature on ice material behaviour is more complicated. The temperature of ice varies from location to location and also from season to season. Within each year, ice temperatures change continuously, with large changes occurring in the two main seasons in the earth's yearly rotation. Thus, ice should be considered site-specific and season-specific.

Temperature has a strong effect on failure stress as lower temperature makes stronger ice. Besides, the structural behaviour of ice cannot be considered independently from the melting-freezing (recrystallisation) process that happens during compression. During failure in polycrystaline ice, micro cracks occur between crystals. Then, seperated crystals change their locations and bond with other crystals by the effect of low temperature. At 
the end of the process, new polycrystal structure occurs. This new structure resists failure force stronger than previous one. The recrystalization phenomenon increases in lower temperature.

\subsubsection{Salinity effect}

Salinity gives the most important difference between freshwater and sea water ice. The freezing point of water decreases with the increase in salt concentration. As the water freezes, it leaves behind the salt, which then dissolves in the remaining water, forming a high-density solution called brine. This brine is surrounded by the fresh water ice. As freshwater freezes faster than high-salinity water, the result is a formation of brine pockets that need comparatively lower temperatures to freeze. Thus, at any given temperature, ice near the brine pockets is weaker and more ductile than ice that is further from those pockets. The weaker ice breaks more easily, forming cracks due to stress concentration.

To better understand the effects of salt on ice, we need to consider a water-salt phase diagram. According to Figure 2, sea ice has brine pockets at temperatures above $-21^{\circ} \mathrm{C}$, and below that temperature the structure consists of only ice and salt particles. Thus, ice strength especially that of sea ice, is very sensitive to temperature. Also, it is a known fact that sea water freezes at a lower temperature $\left(-1.9^{\circ} \mathrm{C}\right)$ than freshwater ice $\left(0^{\circ} \mathrm{C}\right)($ Langleben 1959) as another effect of salinity.

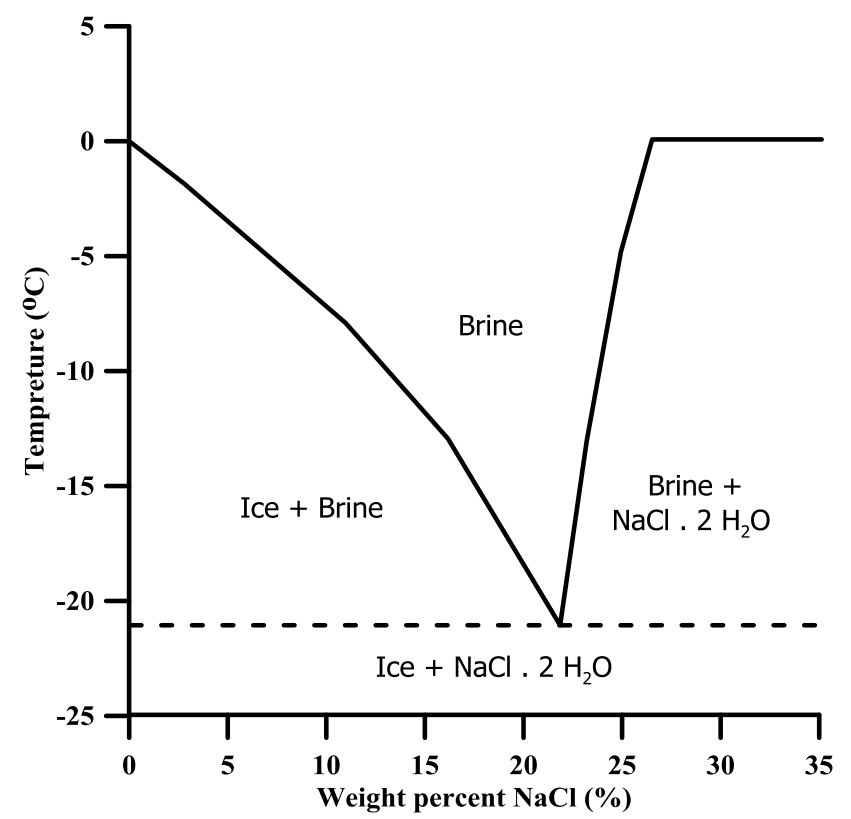

Figure 2. Water-salt phase diagram (Shepard et al. 1976).

Sea ice has a very complex composite structure due to the randomly located pockets of brine and other elements dissolved in the water. Figure 3 shows these phenomena in a schematic way. To characterise the salinity effect of ice, the root brine volume, $\sqrt{v_{b}}$ is often used as the index of ice salinity, where $v_{b}$ can be determined from the Frankenstein and Garner (1967) equation:

$$
v_{b}=S\left(\frac{49.185}{|T|}+0.532\right) \quad \text { for } \quad-0.5^{\circ} C \geq T \geq-22.9^{\circ} C
$$


where $\mathrm{S}$ is salt rate and $\mathrm{T}$ is the temperature in deg. Celsius.

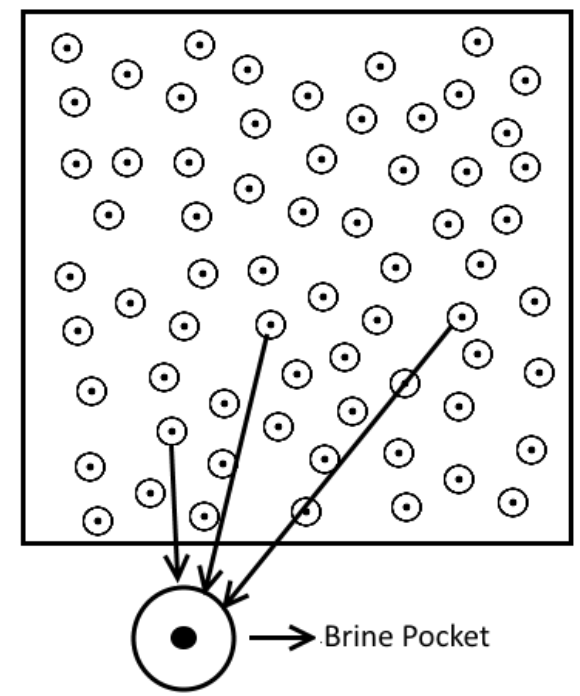

Figure 3. Illustration of brine pockets in ice.

Actually, $90 \%$ of salt is rejected during freezing in sea water, Additionally, high concentrated brine volumes are melting and leaving from the ice because of yearly temperature changes. Therefore, salinity of the icebergs is really low or those are freshwater ice.

\subsection{Strain rate effect}

The structural behaviour of ice is highly dependent on impact speed as similar to metals (Jones 2012). There are a large number of studies which explain the relations between failure stress and strain rate on ice. Failure process of ice is much more complex than metals. It shows both ductile and brittle behaviour. Its failure stress increases up to a certain strain rate, and then sharply decreases. While ice mechanics shows ductile behaviour before this decreament, for higher rates of strain rate ice behaves as brittle. Therefore, the value of this strain rate is accepted as the point of transition from ductile to brittle ice (Schulson 2001). Figure 4 shows the general trend of the compressive stressstrain relationship with different strain-stress. At higher strain rates, most of the deformation in ice is elastic, because there is inadequate time to develop plastic deformation (Dutta et al. 2004).

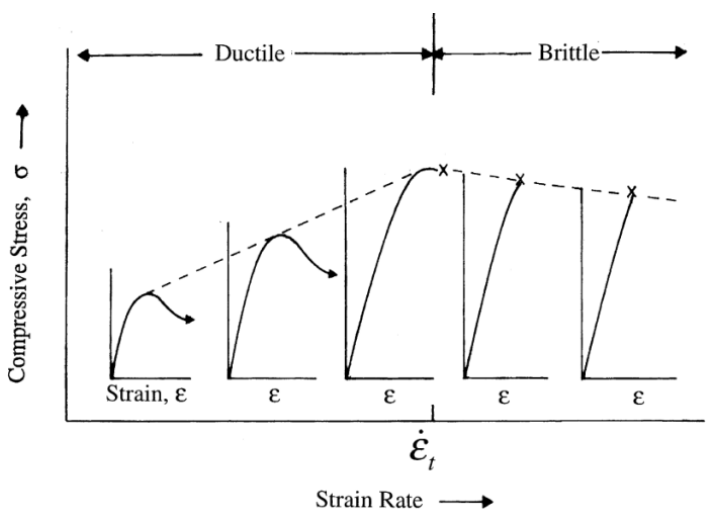

Figure 4. Compressive stress-strain relations of ice materials for different strain rates

(Schulson 2001). 
In the next section, previous studies on literature about effect of temperature, salinity and strain rate on ice mechanics are further reviewed and detailed explanations widely discussed with the help of new conducted experiments.

\section{The Existing and the New Test Database}

The literature includes a number of studies on the effects of different parameters on ice. In addition to the existing test database in the literature, some new test database was also obtained by the laboratory tests. In this paper, we report on 99 tests that were conducted to determine the individual effects of various parameters.

In this section, the new ice experiment procedure is described and literature database collection is indicated in graphs with new results for both sea water and fresh water ice in terms of strain rate, temperature and salinity. Finally, fracture behaviour will examine from the point of strain rate and temperature.

\subsection{New test database}

In authors' test laboratory at Pusan National University, the effects of strain rate, temperature and salinity were examined by compression tests on salt ice, and every test was repeated five times. When one parameter was examined, the other two parameters were kept constant. Specimens were prepared using small ice cubes mixed with $0^{\circ} \mathrm{C}$ sea water and then frozen at $-20^{\circ} \mathrm{C}$ for some 24 hours. For other temperatures, ice was kept at the test temperature for some 30 minutes. Cylindrical specimens were used to avoid edge problems.

Table 2 UTM specification

\begin{tabular}{|l|l|}
\hline Maximum loading capacity & $1 \mathrm{MN}$ \\
\hline Maximum displacement & $150 \mathrm{~mm}$ \\
\hline Loading speed & $-0.01 \sim 2 \mathrm{~mm} / \mathrm{s}$ \\
\hline Temperature control & $-170 \sim 20^{\circ} \mathrm{C}$ \\
\hline
\end{tabular}

The experiment is performed in a cold chamber to keep the target temperature unchanged during tests by using universal testing machine (UTM). Table 2 indicates UTM specification. Figures 5 and 6 show the test set-up and some photos from the experiments. Very thin layer plastic plates were used to avoid heat transfer between ice and test equipment. The UTM was used for compression tests. During tests, displacement and force were measured to characterise the stress-strain relations. $20 \mathrm{kN}$ capacity load cell connected to laptop computer was used to measure loads more accurately. In the following sections, the new test database is discussed together with the existing test database. 


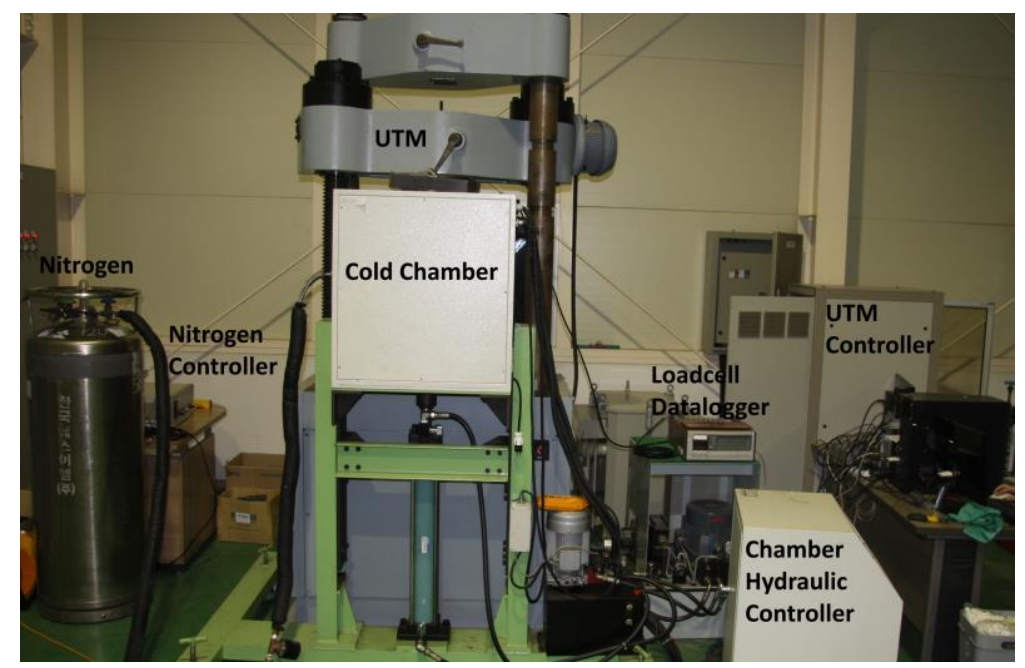

Figure 5. Test set-up for ice in compression at the Korea Ship and Offshore Research Institute at Pusan National University.
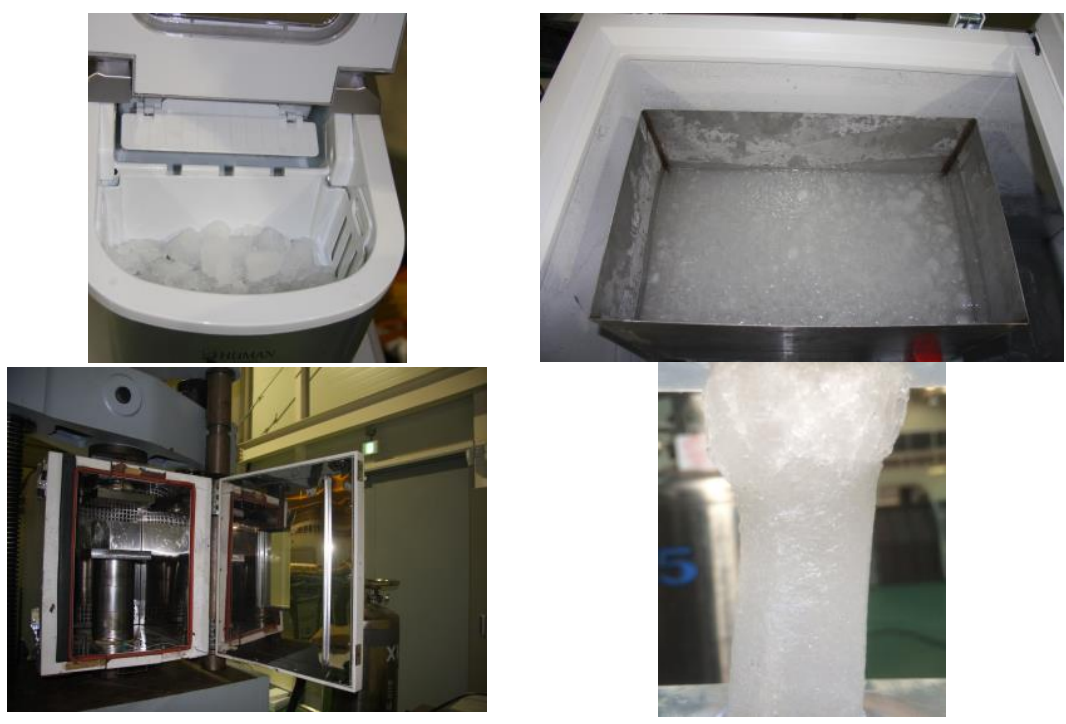

Figure 6. Pictures from the ice experiments.

\subsection{Strain rate effect}

As mentioned in the previous section, ice properties depend on loading speed associated with quasi-static and impact structural responses. Therefore, the strain rate effect is the most commonly studied parameter in the literature. We examined this parameter to determine its effect on the failure stress and the elasticity modulus (Young's modulus).

\subsubsection{Failure stress}

Figure 7 shows the failure stress versus strain rate relationships in freshwater ice and sea ice. Both graphs in Figure 7 show results that are more scattered at the same strain rates in the brittle areas. As the tests were done at a high strain rate, the fractures should have occurred very rapidly. Thus, this scatterness may be due to challenges of 
measurements that must have occurred. In addition, salinity is also an important parameter for sea ice, and the reported tests for sea ice might have been performed on seawater from different locations.

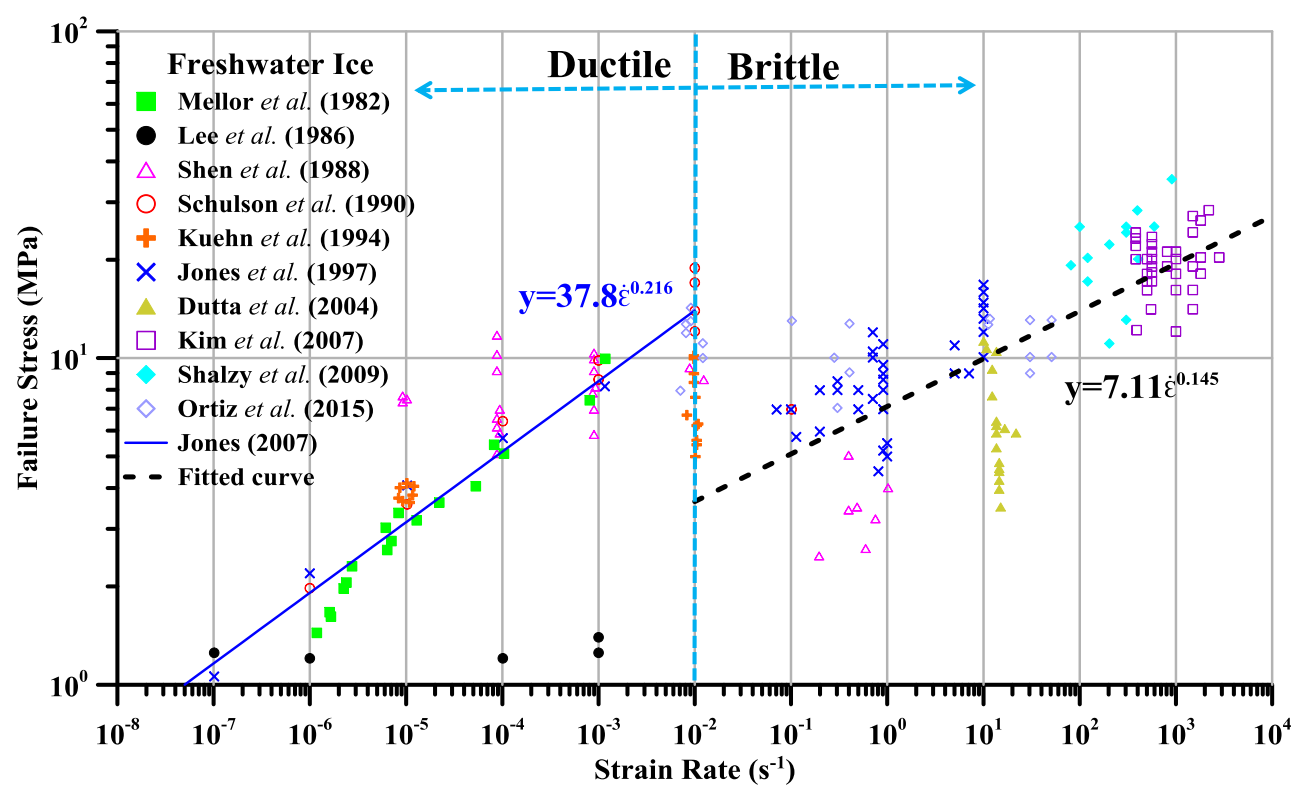

(a) Freshwater ice

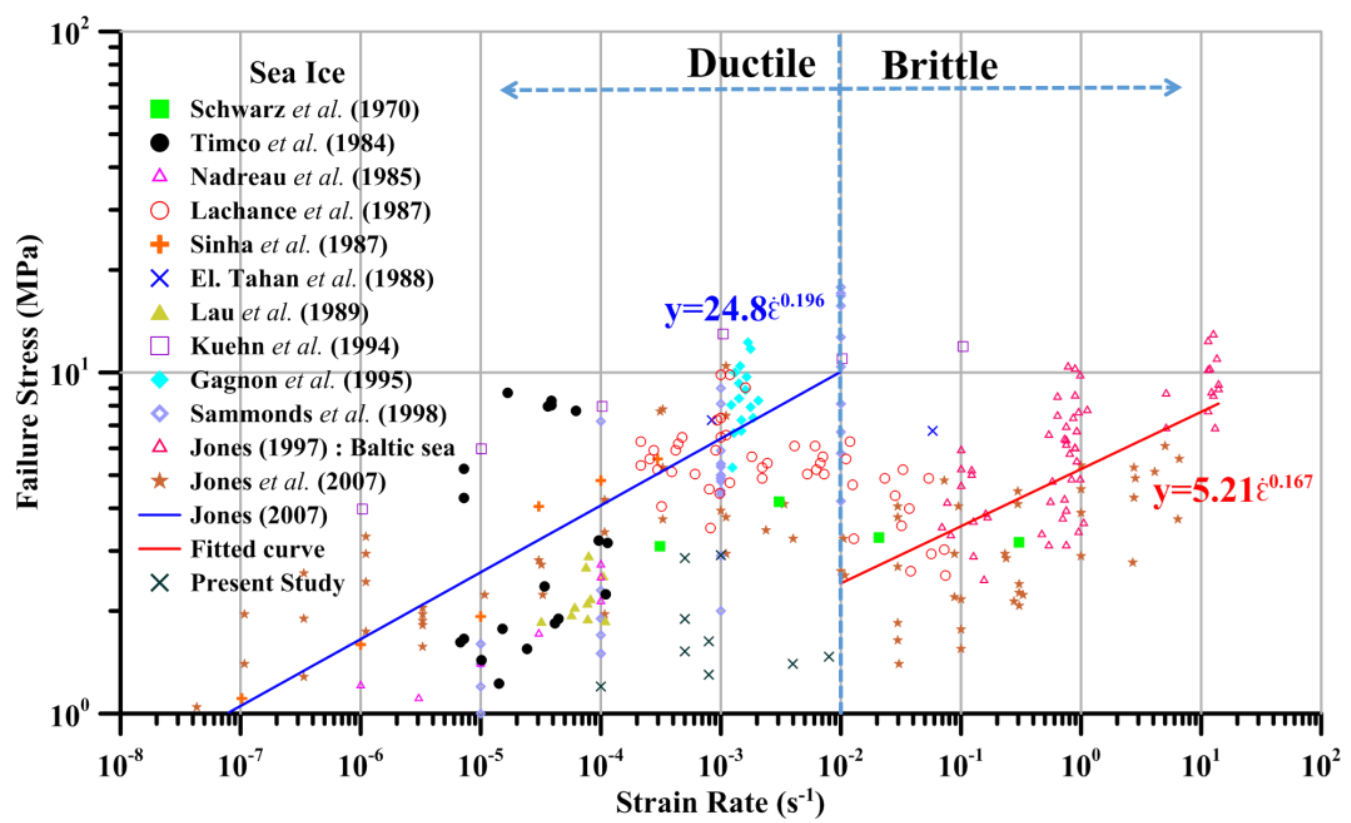

(b) Seawater ice

Figure 7. Failure stress-strain rate relationships for freshwater and seawater ice as per the literature indicated in Tables 3 and 4

Table 3 Temperature during strain rate effect experiments for fresh water ice

\begin{tabular}{|l|l|}
\hline \multicolumn{1}{|c|}{ Authors } & \multicolumn{1}{c|}{ Temperature $\left({ }^{\circ} \mathrm{C}\right)$} \\
\hline Mellor (1982) & -5 and -10 \\
\hline Lee (1986) & -10 \\
\hline Schuldon (1990) & -10 \\
\hline
\end{tabular}




\begin{tabular}{|l|l|}
\hline Jones (1997) & -11 \\
\hline Dutta (2004) & -10 \\
\hline Shazly (2009) & -9 to -12 \\
\hline Ortiz (2015) & -15 and -20 \\
\hline
\end{tabular}

Table 4 Temperature during strain rate effect experiments for sea water ice

\begin{tabular}{|l|l|l|}
\hline \multicolumn{1}{|c|}{ Authors } & \multicolumn{1}{c|}{ Temperature $\left({ }^{\circ} \mathrm{C}\right)$} & \multicolumn{1}{c|}{ Salinity } \\
\hline Schwarz (1970) & $0,-10,-20$ & - \\
\hline Timco (1984) & $-12+-2$ & Beaufaurt sea \\
\hline Sinha (1987) & -10 & First year ice \\
\hline Gagnon (1995) & -11 & Greenland \\
\hline Sammonds (1998) & -10 and -20 & $0.16 \mathrm{ppt}$ \\
\hline Jones (1997) & -11 & $2,4+-0,7 \mathrm{ppt}$ Baltic sea \\
\hline
\end{tabular}

\subsubsection{Young's modulus}

The strain-rate dependence of Young's modulus for ice materials was evaluated by using experimental results from the literature, as shown in Figure 8. All of the results were obtained by mechanical tests where compressive loads were applied to test speciments. The effects of testing methods on the elasticity modulus calculation are explained later in section 4.3.2.

Although it is quite scattered, it is considered that the Young's modulus of freshwater ice is constant regardless of the strain rate, similar to metals, but some limited test results obtained for sea ice by Tabata et al. (1967) tend to decrease significantly as the strain rate increases, as shown in Figure 8(b). However, based on the insights for freshwater ice in Figure 8(a) and also those for temperature as described later in section 4.3.2, it is assumed that the Young's modulus of ice is constant against strain rates, similar to metals, but further studies are certainly encouraged.

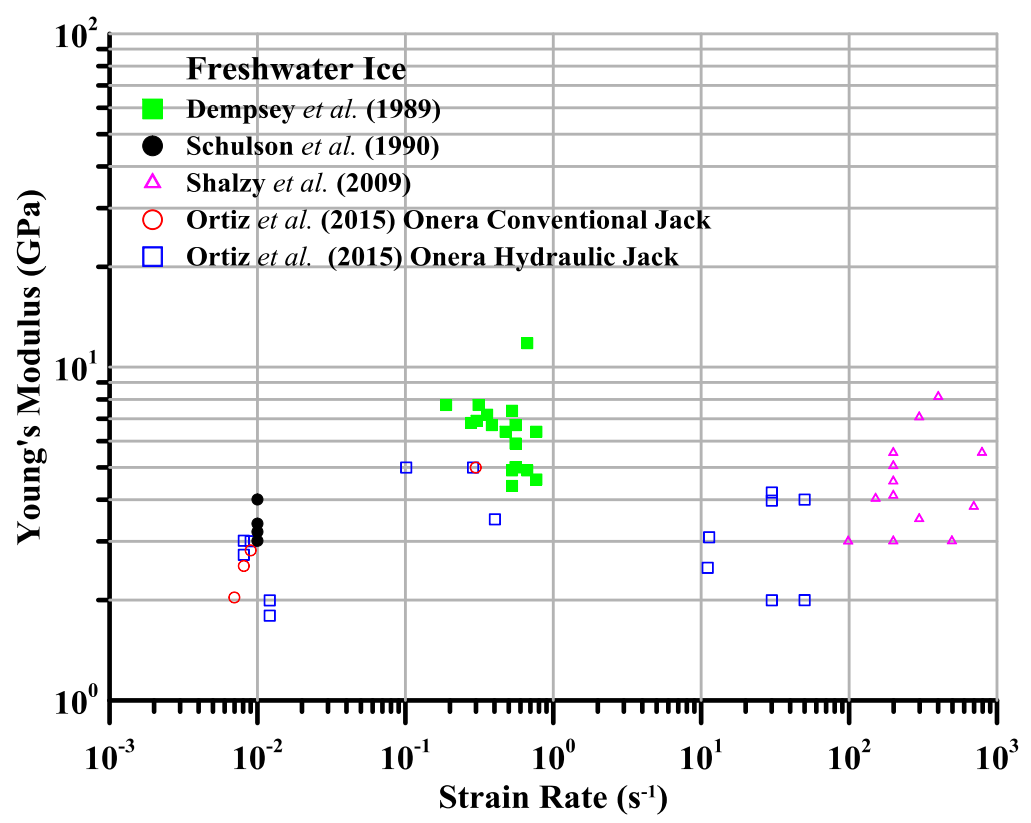

(a) Freshwater ice 


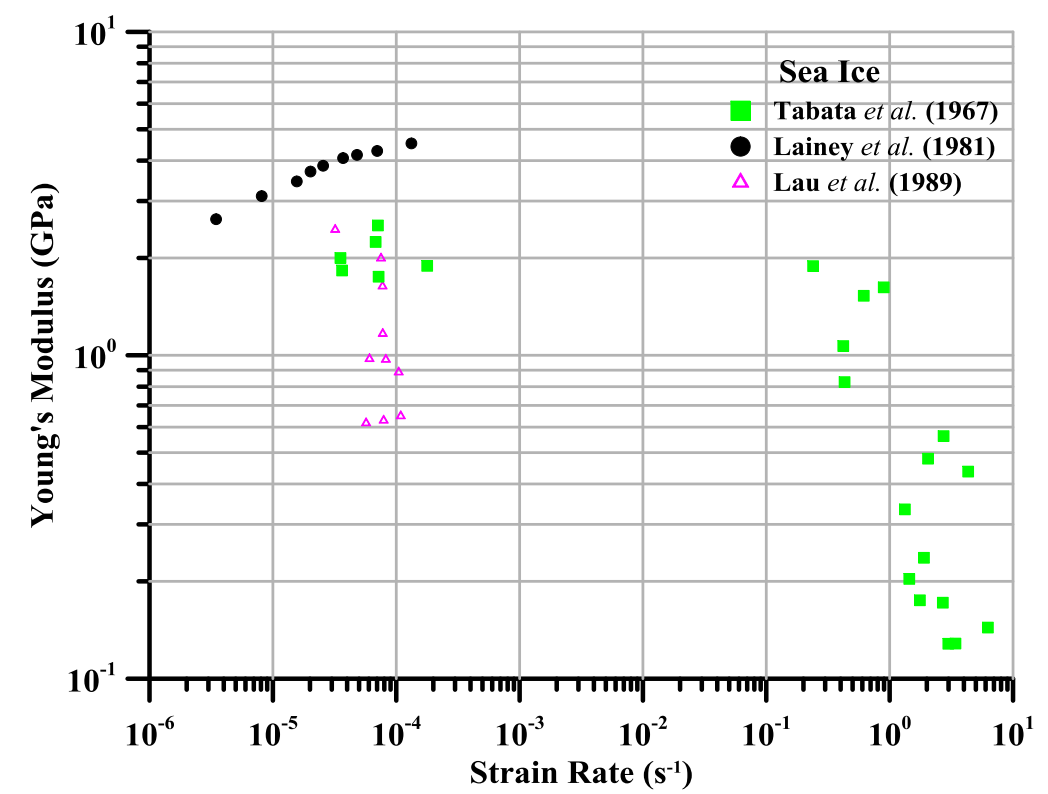

(b) Seawater ice

Figure 8. Young's modulus versus strain rate relationship for freshwater and seawater ice.

\subsection{Temperature effect}

The temperature effect was investigated in terms of failure stress and Young's modulus.

\subsubsection{Failure stress}

Most previous studies have been focused on the effects of temperature on the strength of freshwater and seawater ice. Figure 9 shows the relationship between failure stress versus temperature for freshwater and seawater ice. The laboratory tests showed that temperatures were lower than those found in the previous experiments in the literature. As previously mentioned, there are many uncertainties concerning seawater ice. Therefore, obtaining consistent results is challenging, even in tests repeated with the same equipment.

In general, the strength of ice increases with decreasing temperature. The failure strength of freshwater ice increases with decreasing temperature by $0.35 \mathrm{MPa} /{ }^{\circ} \mathrm{C}$, and the strength of seawater ice increases by $0.4 \mathrm{MPa} /{ }^{\circ} \mathrm{C}$. 


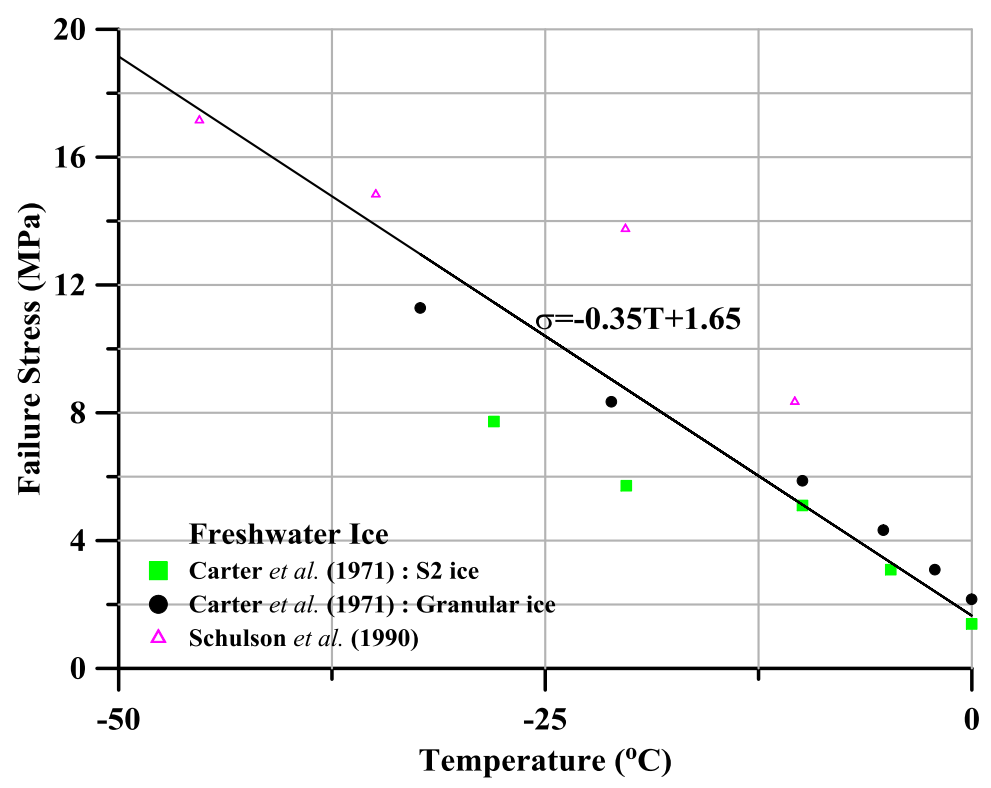

(a) Freshwater ice

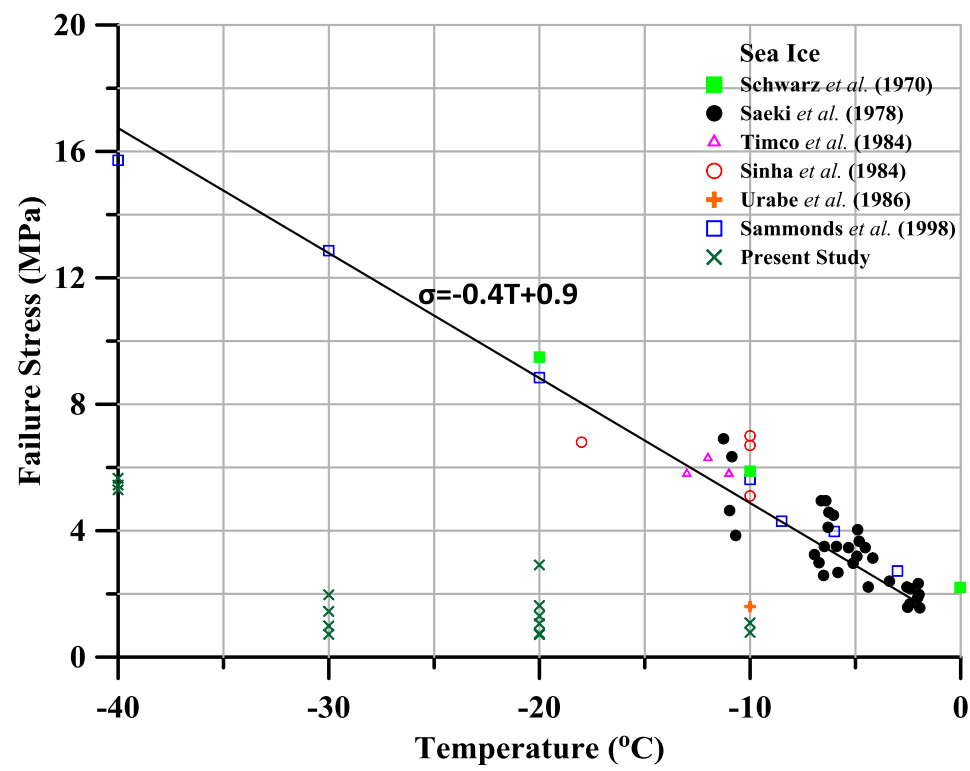

(b) Seawater ice

Figure 9. Effects of temperature on failure stress for freshwater and seawater ice as per the literature indicated in Tables 5 and 6.

Table 5 Strain rates during temperature effect experiments for freshwater

\begin{tabular}{|l|l|}
\hline \multicolumn{1}{|c|}{ Author } & \multicolumn{1}{c|}{ Strain Rate } \\
\hline Carter (1971) & $4 \times 10^{-7}$ to $2.5 \times 10^{-1}$ \\
\hline Carter (1971) & $4 \times 10^{-7}$ to $2.5 \times 10^{-1}$ \\
\hline Schulson (1990) & $10^{-3}$ to $10^{-1}$ \\
\hline
\end{tabular}

Table 6 Strain rates during temperature effect experiments and ice locations for sea water ice

\begin{tabular}{|c|l|l|}
\hline Author & Strain Rate & Remark \\
\hline Schwarz (1970) & $3 \times 10^{-3}$ to $10^{-0}$ & - \\
\hline
\end{tabular}




\begin{tabular}{|l|l|l|}
\hline Saeki (1978) & - & - \\
\hline Timco (1984) & $9 \times 10^{-6}$ to $4.4 \times 10^{-4}$ & Beaufort sea \\
\hline Sinha (1984) & $3 \times 10^{-3}$ to $7 \times 10^{-2}$ & - \\
\hline Urabe (1998) & - & - \\
\hline Sammonds (1998) & $10^{-7}$ to $10^{-2}$ & Multi year sea ice \\
\hline
\end{tabular}

\subsubsection{Young's modulus}

The Young's modulus of ice is challenging to determine, as repeated tests on ice with the same apparatus and the same test conditions do not give consistent results, and the stress-strain curves found in the literature do not validate each other. It is considered that sonic tests are more consistent in providing similar Young's modulus results (Northwood 1947).

Figure 10 shows the relationship between Young's modulus versus the temperature for freshwater and seawater ice, using different testing methods. According to sonic tests, the elasticity modulus of ice is not temperature-dependent. However, the results from other methods are quite different. It is clear from Figure 10(a) that the test results carried out using mechanical methods (compression and bending) give differing results.

There are many different elasticity moduli for the same temperature in the mechanical loading tests. For example, during bending or compression tests there are a number of additional parameters to consider, such as adhesive forces between the equipment and the ice, the equipment temperature, melting that occurs during the test and the recrystallisation effect.

Boyle and Sproule (1931) showed the temperature effect on the elasticity modulus. However, the values they found showed only minor changes that could be considered negligible, and thus, the results could be assumed constant. The dashed rectangle in Figure 10(a) shows the results of several sonic tests, performed by Boyle et al. (1931) and Northwood (1947).

It is clear that the sonic test results are similar, and the other results are not. Thus, the Young's modulus of ice is assumed to be constant against temperatures, based on sonic test results. By using the sonic test, it is found that the average elastic modulus of ice is 9.7 GPa. 


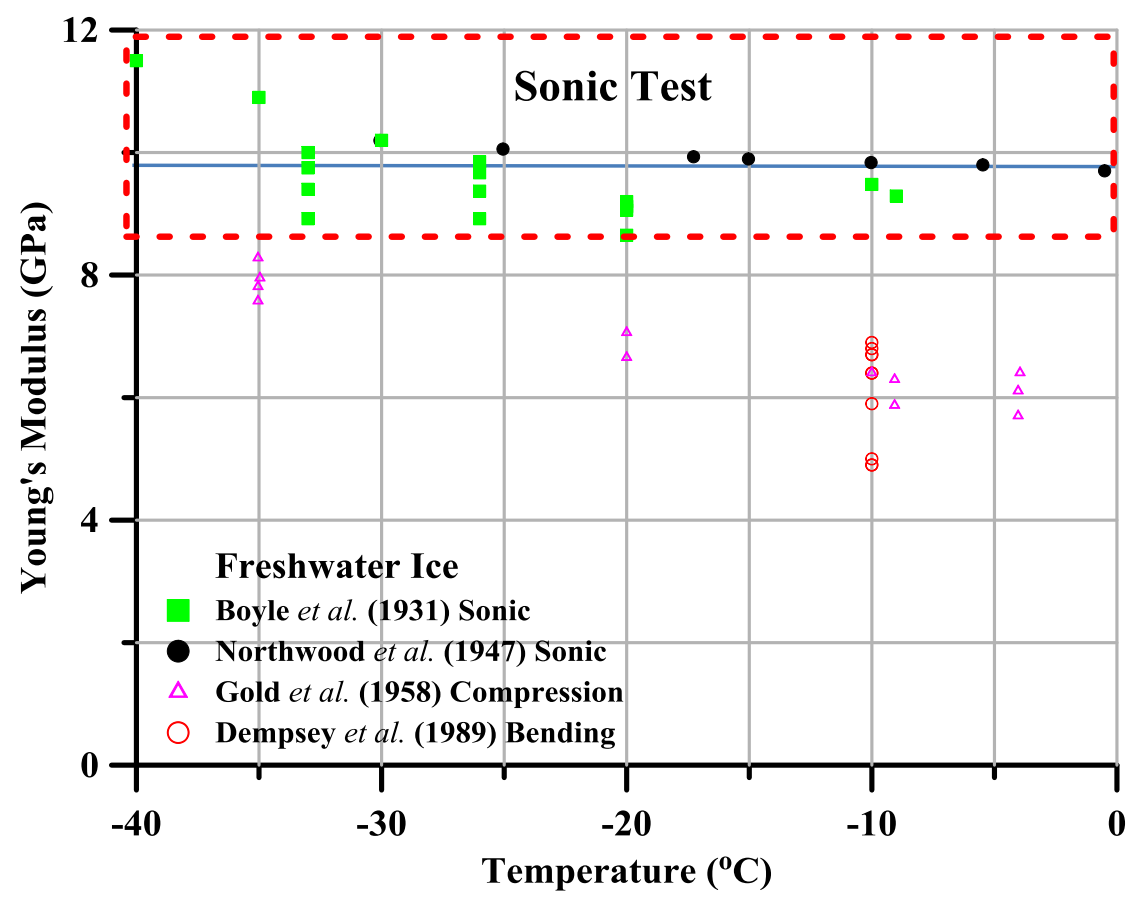

(a) Freshwater ice

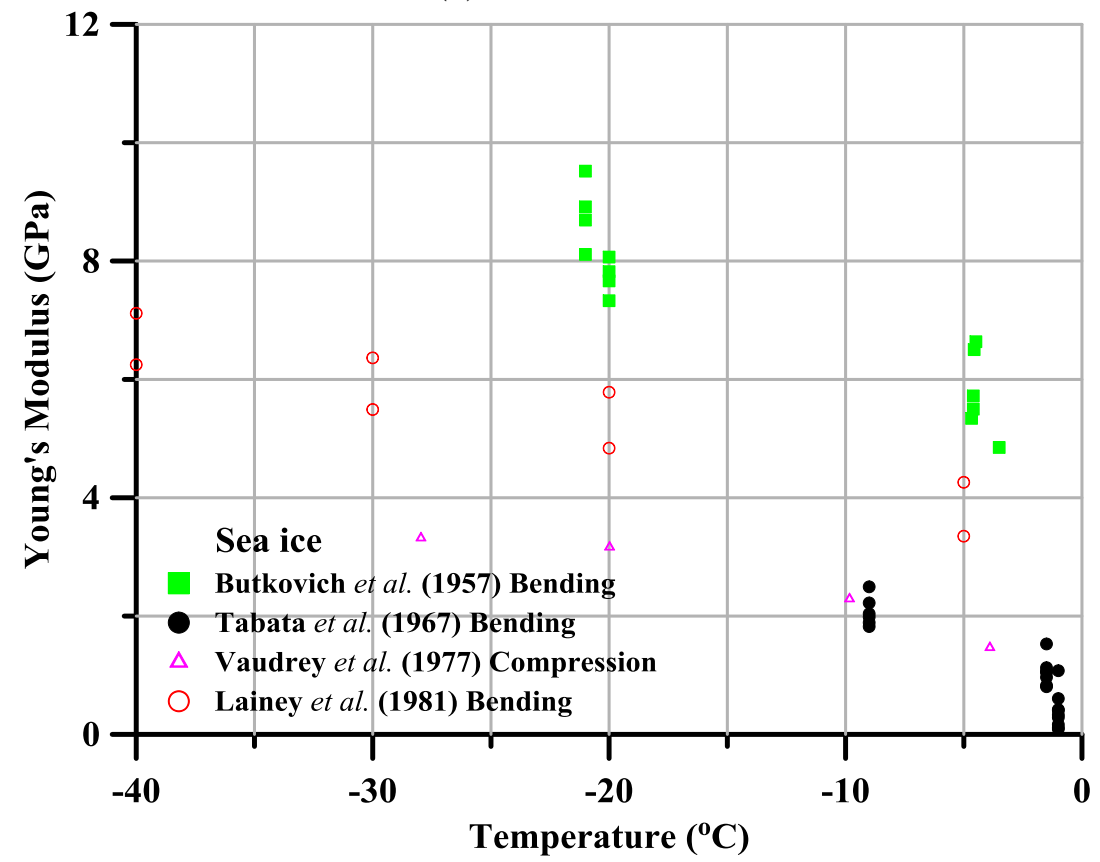

(b) Seawater ice

Figure 10.Young's modulus versus temperature relationship for freshwater and seawater ice.

\subsection{Salinity effect}

Each sea has different metocean properties at different times of the year. For example, Leppäranta and Hakala (1992) studied the structural behaviour of first-year ice in the Baltic Sea. They found that the ice salinity rate was $0.5 \%$, and the density of the ice was $0.9 \mathrm{~g} / \mathrm{cm}^{3}$ in that region. Urabe and Inoue (1988) studied the Antarctic sea ice, finding that its salinity ranged between 0.1 and $0.25 \%$, its density was between 0.75 and $0.9 \mathrm{~g} / \mathrm{cm}^{3}$ and its root brine volume was between 0.025 and $0.05 \%$. 
The salinity of ice also varies with time. Sammonds et al. (1998) gathered data on first-year sea ice from Tuktoyaktuk and Prudhoe Bay, and data on multi-year sea ice from Buckingham Island. The salinity of ice from Tuktoyaktuk and Buckingham Island was between 1 and 3 ppm, but that of the Prudhoe Bay ice was between 4 and 7 ppm. Although the Tuktoyaktuk ice was first-year ice, its salinity was the same as that of the Buckingham Island multi-year ice and salinity of Prudhoe Bay first year ice is higher than Buckingham Island ice. Therefore, instead of finding a general difference between first-year and older ice, site-specific ice examination gives a better strategic idea of ice strength in each locality. The salinity effect on ice strength is shown in Figure 11.

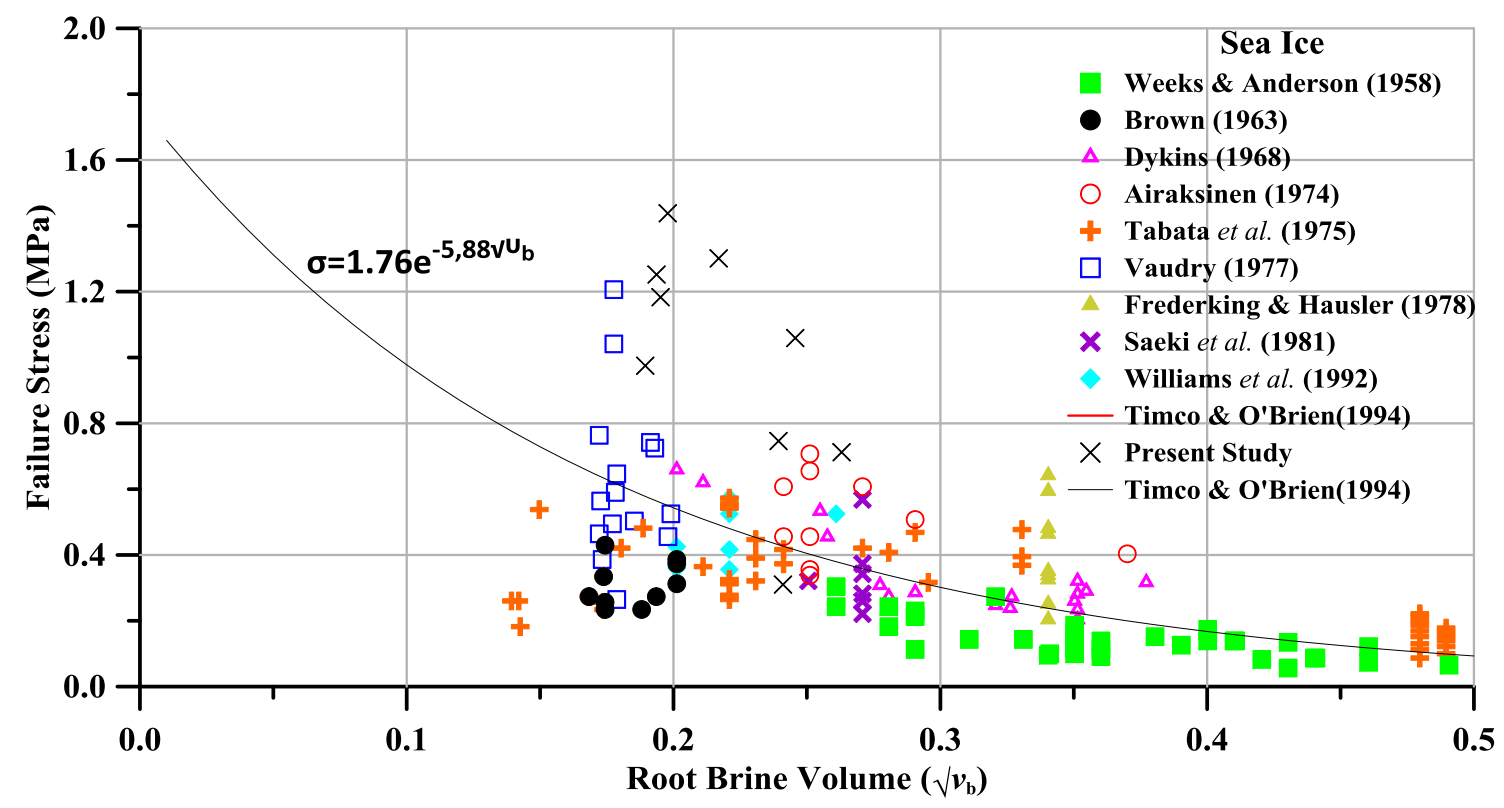

Figure 11. Salinity effects on failure stress.

\subsection{Fracture mechanics of ice}

Ice fracture behaviour is also affected by strain rate and temperature. In this section, the main aim is to measure the material resistance against fracture in stress-strain relations, depending on the strain rate and the temperature, although this information is not directly used to formulate the constitutive equation on ice materials. Those are very important to calculate accurately main inputs of discrete element methods which can be used for ice modelling in FEM.

\subsubsection{Strain rate effect on fracture}

Previously, the studies of ice behaviour have examined the strain rate, and in this section, how fracture resistance changes by the strain rate will be examined. Figure 12 shows the relation between the strain rate fracture toughness for freshwater and sea water. The fitted curve equation may be used to calculate the energy-release rate for a discrete element model of ice behaviour. 


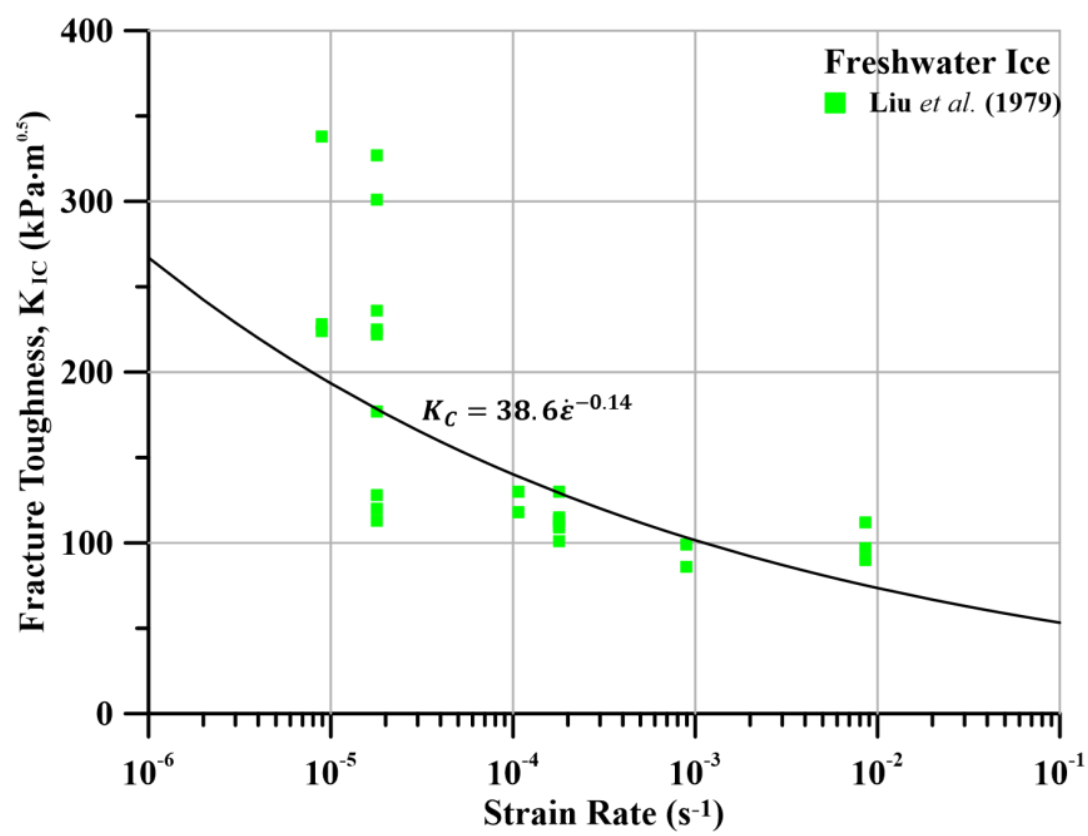

(a) Freshwater ice

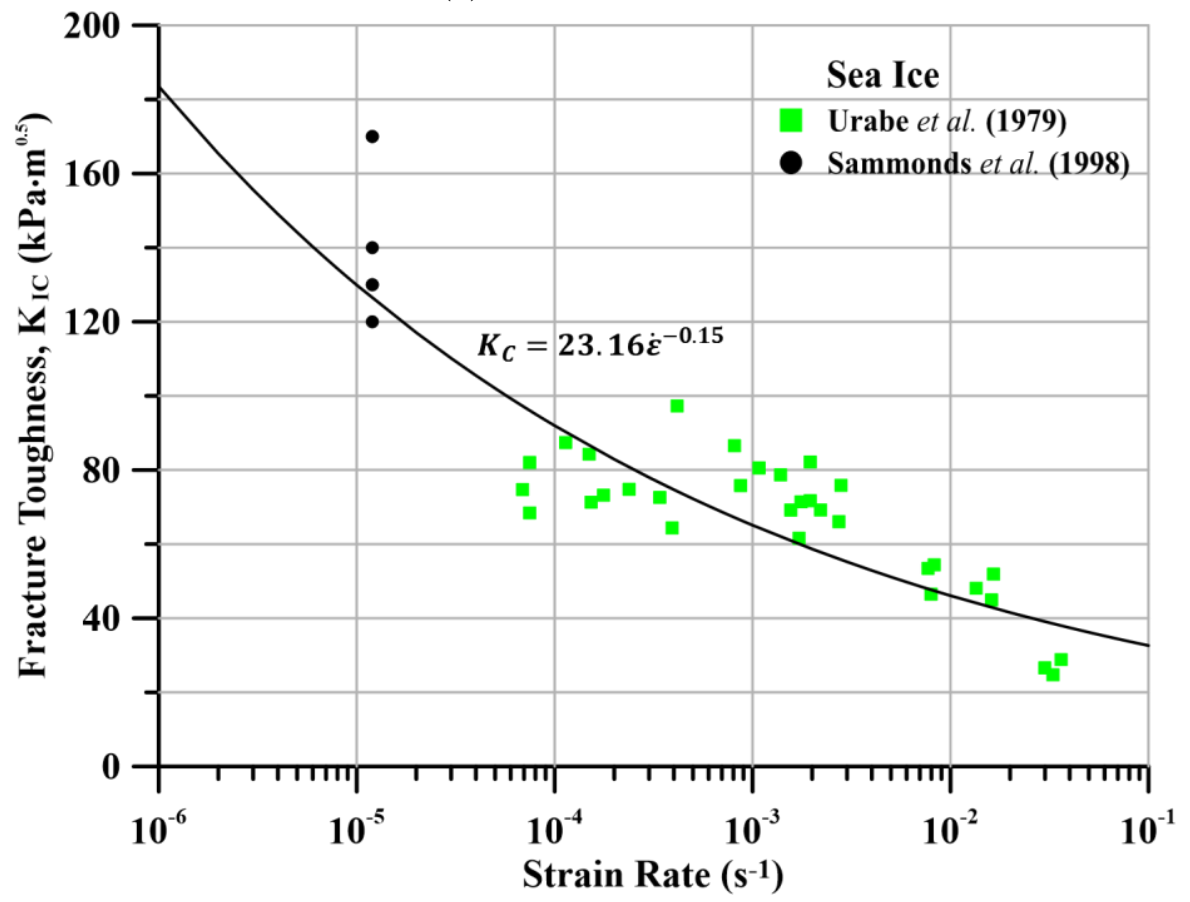

(b) Seawater ice

Figure 12. The fracture toughness-strain rate relationship for freshwater and seawater ice.

\subsubsection{Temperature effect on fracture}

Temperature is another important parameter for fracture resistance. Figure 13 illustrates the relationship between temperature and fracture toughness for freshwater and seawater ice. 


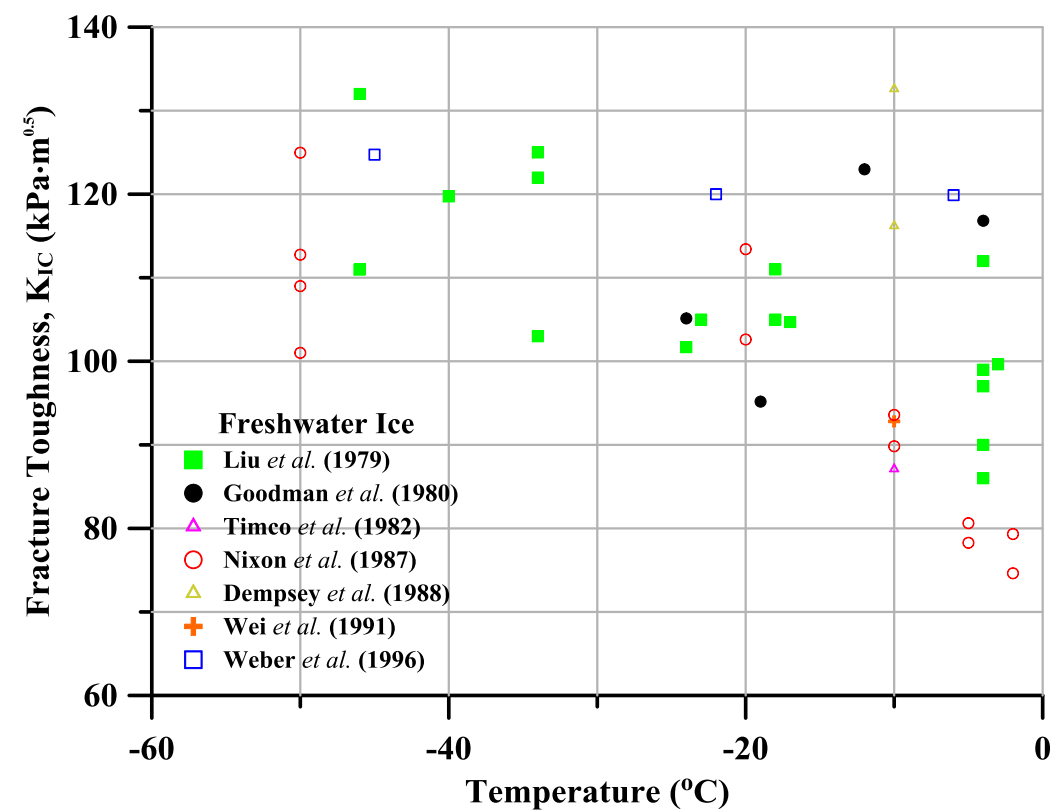

(a) Freshwater ice

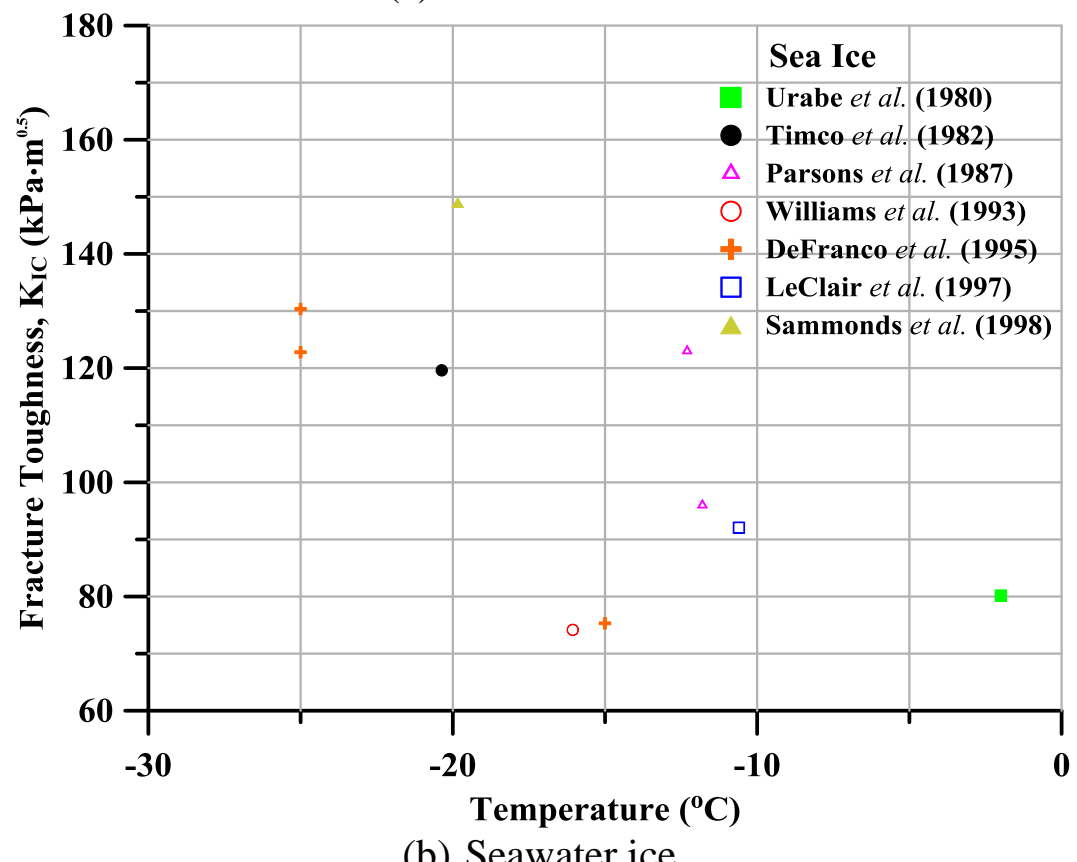

Figure 13. The fracture toughness versus temperature relationship for freshwater and sea ice.

\section{Proposal of a New Constitutive Equation on Ice Materials}

As a structural engineering problem, ice material can be dealt with in a similar way to metals. Mechanical properties of ice materials are affected by site-specific and seasonspecific conditions, and they must then be defined in association with metocean data for the purpose of engineering and design practices.

This section formulates a new constitutive equation on ice materials associated with quasi-static and impact structural responses. Section 2.1 explained that ice has ductile behaviour under a certain level of strain rate and shows brittle behaviour at upper band of the critical strain rate. As per Figure 7, it is obvious that ice material usually follows brittle behaviour although it may follow ductile behaviour in a quasi-static condition with a very 
low strain rate $\dot{\varepsilon}$ at $\dot{\varepsilon} \leq \dot{\varepsilon}_{c r}$ where $\dot{\varepsilon}_{c r}$ is the critical strain rate that distincts between ductile and brittle behavior. $\dot{\varepsilon}_{c r}=10^{-2} / s$ can be used for an example. In this regard, the present study proposes the constitutive equation that is classified into two groups, namely for ductile and brittle behaviour, as follows.

(i) Ductile model when $\dot{\varepsilon} \leq \dot{\varepsilon}_{c r}$

$$
\sigma=\left\{\begin{array}{ll}
E \varepsilon & \text { for } \sigma<\sigma_{F} \\
\sigma_{F} & \text { for } \sigma=\sigma_{F} \\
0 & \text { for } \delta \geq \delta_{C}
\end{array}\right. \text { for ductile behaviour }
$$

(ii) Brittle model when $\dot{\varepsilon}>\dot{\varepsilon}_{c r}$

$$
\sigma=\left\{\begin{array}{lll}
E \varepsilon & \text { for } & \sigma<\sigma_{F} \\
0 & \text { for } & \delta \geq \delta_{C}
\end{array} \quad\right. \text { for brittle behaviour }
$$

where $\sigma=$ engineering stress, $\varepsilon=$ engineering strain, $E=$ Young's modulus which may be taken as $9.7 \mathrm{GPa}$ for freshwater or sea ice material, $\sigma_{F}=$ failure stress, $\delta=$ separation and $\delta_{C}=$ crack opening displacement. $\delta$ and $\delta_{C}$ are phenomenological expressions that are to be described in section 5.2.

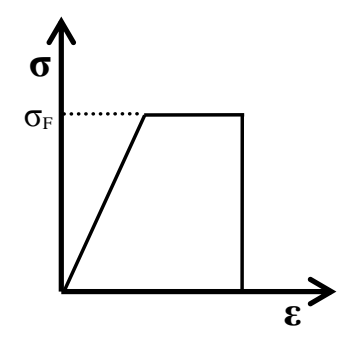

(a) Ductile model

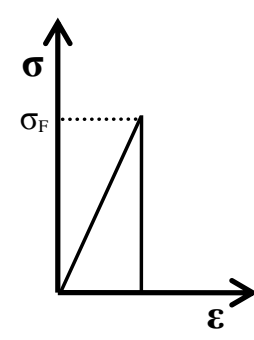

(b) Brittle model

Figure 14. Schematic of material models for ice

In the following, the remaining parameters of physics to be defined in equations (2) and (3), namely $\sigma_{F}$ and $\delta_{C}$ are now determined as a function of strain rate, temperature and salinity where the effect of grain size is not considered. Again, they must be dependent on site-specific and season-specific conditions and thus metocean database should be used. However, as an illustrative example, this section defines $\sigma_{F}$ and $\delta_{C}$ based on the existing and the new test database described earlier. To define $\delta_{C}$ a fracture model of ice is suggested separately based on separation of elements which can calculate from fracture toughness.

\subsection{Failure stress $\sigma_{F}$}


Johnson and Cook (1983) suggested a model used for metals to represent the relationship between engineering stress and engineering strain, taking into account the effects of strain rates and temperatures. The original Johnson-Cook model is formulated as follows.

$$
\sigma=\left(A+B \varepsilon_{p}^{n}\right)\left(1+C \ln \frac{\dot{\varepsilon}}{\dot{\varepsilon}_{o}}\right)\left[1-\left(\frac{T}{T_{o}}\right)^{m}\right]
$$

where $\varepsilon_{p}=$ plastic strain, $\dot{\varepsilon}=$ strain rate, $\dot{\varepsilon}_{o}=$ reference strain rate, $T=$ temperature, $T_{o}=$ reference temperature, and $A, B, C, n$, and $m$ are the test coefficients of materials.

The original Johnson-Cook model does not take into account the effect of salinity, and temperature is considered to be affected linearly on ice strength against it. In the present study, equation (4) is modified to take into account the effects of salinity and temperature as follows.

$$
\sigma=A\left[1+B \ln \left(\frac{\dot{\varepsilon}}{\dot{\varepsilon}_{o}}\right)\right]\left[C\left(\frac{T}{T_{o}}\right)\right]\left[D \ln \left(\sqrt{\frac{v_{b}}{v_{b o}}}\right)\right]
$$

where $D$ is the test coefficient associated with the salinity, $v_{b}$ is the brine volume as defined in equation (1) and $v_{b o}$ is the reference brine volume. In this model, time dependency of ice, hardening and viscous effects are neglected to simplify the problem.

The model also helps us to put all of these parameters together into one governing equation. It is necessary to create a constitutive material model that can adequately represent a wide range of strain rates, temperatures and salinity levels. Although the stress-strain curves of ice as obtained from experimental results are inconsistent, the trends of the curves can be used.

For more refined design and engineering purpose, it is suggested to define the test coefficients in equation (5) from testing for ice cut out of icebergs associated with sitespecific and season-specific conditions. In the following, the test coefficients are defined based on the existing and the new test database as an illustrative example which can still be beneficial for the practical purpose of design and engineering.

The strength-strain rate relations for freshwater and seawater ice are examined in Figure 7. It can be seen that the critical strain rate $\dot{\varepsilon}_{c r}$ can be taken as $\dot{\varepsilon}_{c r}=10^{-2} / \mathrm{s}$. Below this value, ice behaves as a ductile material, and at higher values the ice behaves as a brittle material (Schulson 2001). Although the strength values are scattered, the trend in strength values can be useful as a general reflection of freshwater ice behaviour.

Furthermore, Jones (2007) suggested equation (6) for ice in the ductile area. In a similar way, a curve can be fitted for ice in the brittle area as formulated by equation (7).

$$
\begin{aligned}
& \sigma_{F}=37.8 \dot{\varepsilon}^{0.216} \text { for ductile behaviour } \\
& \sigma_{F}=7.11 \dot{\varepsilon}^{0.145} \text { for brittle behaviour }
\end{aligned}
$$

In Figure 9, the failure stress versus temperature relationships are fitted based on the test database for freshwater and sea ice as follows. 


$$
\begin{aligned}
& \sigma_{F}=-0.35 T+1.65 \text { for freshwater ice } \\
& \sigma_{F}=-0.40 T+0.9 \text { for seawater ice }
\end{aligned}
$$

As previously discussed, salinity has important effects on ice strength, as is shown in Figure 11. For predicting the effect of salinity on ice, Timco and O'Brien (1994) suggested equation (10). In Figure 7, the strain rates of freshwater and seawater ice and the graphic fitted curves of the equations' ratios are almost constant. Also in Figure 9, the tangents of the freshwater and seawater ice temperature are similar. Therefore, it can be said that the effect of salinity is independent from the strain rate or temperature.

$$
\sigma_{F}=1.76 e^{-5.88 \sqrt{v_{b}}}
$$

According to the characteristic curves which were fitted with the test database, the coefficients of equation (5) can now be calculated for arbitrary strain rate, temperature and salinity by keeping other two parameters constant as indicated in Table 7.

Table 7. Reference parameters for seawater ice associated with equation (5)

\begin{tabular}{|l|c|}
\hline$\dot{\varepsilon}_{o}$ & $10^{-2}$ \\
\hline$T_{o}$ & $-10^{\circ} \mathrm{C}$ \\
\hline$\sqrt{v_{b o}}$ & 0.5 \\
\hline
\end{tabular}

In equation (5), $A$ is the constant, which is the yield stress when the strain rate is equal to the reference strain rate. The test coefficients in equation (5) are defined based on the previous section's findings concerning ice structural properties. This equation is suitable for conditions of between 0.005 and 0.5 root brine volume. For freshwater ice, the salt parameters should be ignored. Considering the existing and new test database and insights noted above, the coefficients in equation (5) are then suggested as indicated in Table 8.

Table 8.Test coefficients in equation (5)

\begin{tabular}{|c|c|c|}
\hline & $\begin{array}{c}\text { Ductile } \\
\left(\left[10^{-5}, 10^{-2}\right] \text { strain rate }\right)\end{array}$ & $\begin{array}{c}\text { Brittle } \\
\left(\text { After } 10^{-2} \text { strain rate }\right)\end{array}$ \\
\hline$A$ & 11.74 & 3.64 \\
\hline$B$ & 0.08 & 0.37 \\
\hline$C$ & 0.8 & 0.8 \\
\hline$D$ & -0.4 & -0.4 \\
\hline
\end{tabular}

Commercial finite element programs have extensive material model library. Additionally, they have user-defined material model (UMAT) option for analysts. UMAT subroutine is implemented to half compiled source code of such programs. To implement the present model into such programs, the following assumptions may be applied.

- Temperature and salinity are assumed to be unchanged during ice impact. Therefore, temperature and salinity parameters are not updated during the calculations.

- Strain rate shall be calculated at every iteration and stress updates based on the constitutive equation as per the new strain rate at the iteration step. 


\subsection{Crack opening displacement $\delta_{C}$}

To define the crack opening displacement, $\delta_{C}$ in equations (2) and (3), a fracture model must be applied. Fracture mechanism of ice cannot be described simply definition of fracture strain or fracture stress. As discussed before, the fracture behaviour also depends on the conditions. Thus, energy based fracture definition can be more reliable because the energy is the integration of stress and strain. On the other hand, previous studies of ice have shown that ice grains tend to separate in two ways: through ductile or brittle fracturing. If at a given speed of impact the fracture area recrystallizes during impact, the ice shows ductile behaviour (Dutta et al. 2004; Jones 2007). For brittle behaviour, discrete finite element modelling seems to be an adequate approach (Lau et al. 2011). However, for ductile behaviour, a new approach is necessary. If this type of behaviour is modelled with discrete elements, then a high-friction coefficient between the discrete particles can be useful to model the recrystallization.

The cohesive zone model (CZM) is one type of discrete element method and generally used to model composite material. In the CZM model, a zero thickness layer between the elements is defined, and when this layer reaches a sufficient energy level, the cohesive element between the bulk elements fails, and the fracture initiates. Figure 15 illustrates the cohesive element method. The narrow band in the figure is termed the cohesive zone and is assumed to exist ahead of a crack tip, which represents the fracture process zone. According to the CZM method, the crack-opening forces are calculated by using the relative displacement between adjacent nodes. It is considered that fractures occur when the energy-release rate is greater than the fracture-resistant toughness of the material.

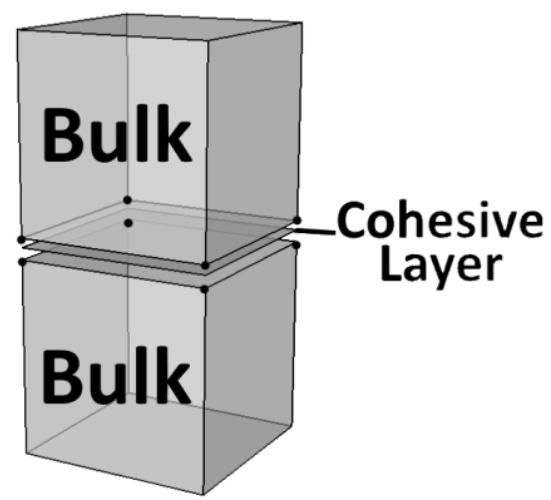

Figure 15. Cohesive zone model.

Gürtner (2009) used the CZM model to simulate ice interaction between ice sheets or layers and multiple protection piles. The simulation results were then compared with experimental test results. Bjerkås et al. (2010) studied the cohesive dynamic response compared to the static response for a lighthouse. In addition, Hilding et al. (2012) used the CZM model to investigate a full-scale offshore lighthouse that was penetrated by drifting ice. The CZM model has been preferred in several previous studies for solving the problem of fractures in the ice, as it follows the traction separation law. When numerically simulating ice by using the CZM model, it is necessary to introduce a zero thickness element around the element whose strength is defined by using the traction separation law.

To understand and solve the problem scientifically or numerically, a fracture is defined as the making of two surfaces by breaking a material, and the energy dissipated during this process per unit of the newly created fracture's surface area is the strain 
energy-release rate. This rate is calculated by using a fracture toughness and elasticity modulus (Liu \& Miller 1979).

$$
\mathrm{G}=\mathrm{K}^{2}\left(1-v^{2}\right) / E
$$

where $\mathrm{G}$ is the strain energy-release rate, $\mathrm{K}$ is the fracture toughness, $v$ is the Poisson ratio and $\mathrm{E}$ is the elasticity modulus.

Ice fracture toughness is strain-rate dependent. Therefore, the energy-release rate is also strain-rate dependent. The existing explicit finite element programs do not involve a strain-rate dependent CZM model, because the CZM model is a phenomenological model, and it is modelled with a zero thickness virtual element between the other elements. Instead of using the strain rate, some studies have used the fracture-opening speed. As discussed in the previous section, the relations between strain rate and energy-release rate have been previously explored in the literature on ice. However, for modelling ice fractures with the CZM model, the strain rate-energy-release rate should be converted to the fracture-opening speed-energy-release rate relation. Previous studies have used a trial and error method to find this relation based on the trend of the strain rate-fracture toughness relation.

The softening and hardening behaviour predicted by the CZM model is governed by the traction-separation curve. This curve defines the resistance of the material to cracking. The area under this curve gives the fracture energy (Mulmule \& Dempsey 1998). It has been found that crack-opening displacements involve creep deformation. However, it is hard to measure the creep for fresh water and sea ice, due to the non-homogeneity of ice in terms of ice grains, brine volumes and other impurities (Mulmule \& Dempsey 1999).

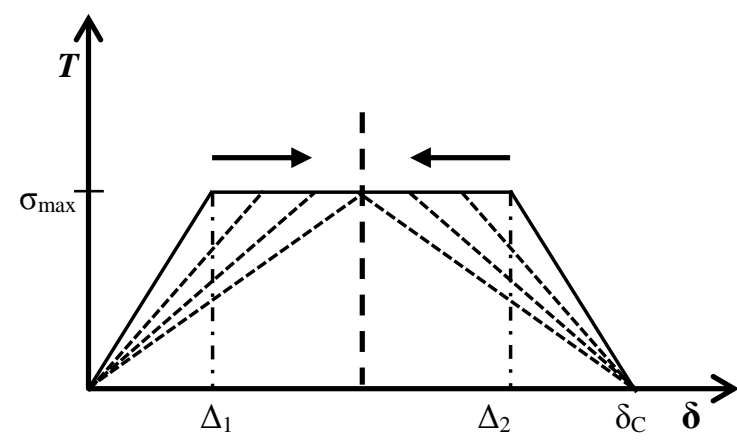

Figure 16. Fracture-opening speed dependent traction-separation curve.

Not only does the energy-release rate change based on the strain rate, but the material behaviour also changes from ductile to brittle. The traction-separation curve may be defined by the brittle or ductile behaviour of the ice. It is known that the area under the traction-separation curve gives the fracture energy. As we can see in Eq.16, separation is dependent on the fracture energy and the traction-separation curve. With an increase in the rate of loading, the ice fracture changes from ductile to brittle. When this change occurs, the traction separation changes according to changes in the strain rate. A fractureopening speed dependent traction-separation curve may be better for predicting ductile or brittle behaviour through one model. Figure16 shows the fracture-speed dependent traction-separation model based on the work of Tvergaard and Hutchinson (1992) that can be formulated as follows. 


$$
\delta_{C}=\frac{G}{A_{T S L C} \sigma_{\max }}
$$

where $\delta_{C}$ is the opening displacement, $G$ is the strain-energy release rate, $A_{T S L C}$ is the area under traction-separation curve and $\sigma_{\max }$ is the maximum traction force.

\section{Concluding Remarks}

Due to global warming, merchant cargo ship operation in arctic areas has become feasible. Also, offshore platforms are increasingly used to develop oil and gas in arctic areas. In these situations, ships and offshore structures can be exposed to ice loads associated with collision impact. An adequate ice strength model is needed to accurately characterise the interaction effects between ships or offshore platforms and ice.

A review of the literature shows that a number of useful studies have been conducted on ice at material level and structure level. Here, we focused on collecting and reviewing many existing studies of the properties of ice, on conducting extensive experiments, and on compiling the database such that they can be used to better understand the structural behaviour of ice in relation to different impact speeds and metoceanic conditions. The available database can also be used for site-specific assessment, depending on the salinity and temperature at each particular location.

We examined ice structures in terms of the impact speed or strain rate effect. We found that compression tests are inadequate to describe elastic behaviour, as the Young's modulus varies a great deal in tests done even using the same equipment and under the same conditions. Non-destructive testing methods showed more reliable results. Sonic test results indicated that the elastic behaviour of ice may be assumed to be constant.

Previous studies of ice have also shown that the strain rate, temperature and salinity are important parameters in the structural behaviour of ice. Based on these studies and the trends of stress-strain curves obtained by compression tests, the relationships between ice strength and these various parameters were elucidated. It was also noted that laboratory produced sea ice specimens are less strong than real sea ice according to the collected database. During the preparation of sea ice in the laboratory it is cared to make homogeneous specimen and to get under control uncertainties such as air bubbles and salinity. For the real sea ice, those are random changes by metocean conditions. This may certainly cause the strength difference.

Based on the insights and findings of the test database in the literature and the new laboratory test results developed in the present study, a new constitutive equation used for ice materials was proposed where the effects of strain rate, salinity and temperature are taken into account. The new constitutive equation is obvious as it's formulation is classified into two groups that represent ductile and brittle behavior as per the critical strain rate. To define the failure stress in the new constitutive equation, the Johnson-Cook model originally used for metals was used by modifying it to take into account the effects of salinity and temperature properly. Also, a fracture model was used to define the crack opening displacement in the constitutive equation.

A separate study associated with the MSc thesis (Kumar 2016) of the second author was undertaken to validate the applicability of the proposed model where a comparative study of existing ice models was performed. A separate paper is also under development to illustrate the applied examples of the proposed model where structural crashworthiness 
is examined in association with collisions between ships and ice-ridges. This study is part of the PhD thesis of the first author (Ince 2016).

\section{ACKNOWLEDGEMENTS}

The study was undertaken at the Lloyd's Register Foundation Research Centre of Excellence at Pusan National University. Lloyd's Register Foundation (LRF), a UK registered charity and sole shareholder of Lloyd's Register Group Ltd, invests in science, engineering and technology for public benefit, worldwide. This work was supported by a 2-Year Research Grant of Pusan National University.

\section{REFERENCES}

Arakawa M, Maeno N. 1997. Mechanical strength of polycrystalline ice under uniaxial compression. Cold Reg Sci Technol [Internet]. [cited 2015 Mar 16]; 26:215-229. Available from: http://www.sciencedirect.com/science/article/pii/S0165232X97000189

Bjerkås M, Albrektsen A, Gürtner A. 2010. Static and Dynamic Ice Actions in the Light of New Design Codes. In: 29th Int Conf Ocean Offshore Arct Eng Vol 4 [Internet]. [place unknown]: ASME; [cited 2015 Jul 29]; p. 733-739. Available from: http://proceedings.asmedigitalcollection.asme.org/proceeding.aspx ?articleid=1617702

von Bock und Polach R, Ehlers S. 2013. Model scale ice - Part B: Numerical model. Cold Reg Sci Technol [Internet]. 94:53-60. Available from: http://dx.doi.org/10.1016/j.coldregions.2013.06.009

Butkovich TR. 1959. On the mechanical properties of sea ice, Thule, Greenland, 1957. Wilmette, Illinois.

Carter D, Michel B. 1971. Lois et mecanismes de 1'apparente fracture fragile de la glace de riviere et de lac. [place unknown]; [cited 2015 Apr 30]. Available from: https://scholar.google.com/scholar?q=Lois+et+M\%E2\%80\%98ecanismes+de+1\%E2\%8 0\%99apparente+Fracture+Fragile+de+la+glace+de+Rivi\%E2\%80\%98ere+et+de+Lac\& $\mathrm{btnG}=\& \mathrm{hl}=\mathrm{en} \& \mathrm{as} \_\mathrm{sdt}=0 \% 2 \mathrm{C} 5 \# 0$

Cole DM. 1998. Modeling the cyclic loading response of sea ice. Int J Solids Struct. 35:4067-4075.

Dempsey JP, Wei Y, Yingchang W. 1989. Fracture toughness KQ and fractography of S1 type freshwater ice. In: ICF7 [Internet]. Houston (USA); [cited 2015 Apr 30]; p. 34213428.

Available

from:

http://www.gruppofrattura.it/ocs/index.php/ICF/ICF7/paper/download/3700/8462

Dutta PK, Cole DM, Schulson EM, Sodhi DS. 2004. A fracture study of ice under high strain rate loading. Int J Offshore Polar Eng. 14:182-188.

Duval P, Ashby MF, Andermant I. 1983. Rate-controlling processes in the creep of polycrystalline ice. J Phys Chem. 87:4066-4074.

El-Tahan H, Swamidas ASJ, Arockiasamy M. 1988. Impact indentation strength of iceberg and artificial snow ice. J Offshore Mech Arct Eng [Internet]. [cited 2015 Apr 30]; 110:87.

Available

from:

http://offshoremechanics.asmedigitalcollection.asme.org/article.aspx?articleid=1452449

Gagnon R. 2004. Analysis of laboratory growler impact tests. Cold Reg Sci Technol 
[Internet]. [cited 2014 Dec 7]; 39:1-17. Available from: http://linkinghub.elsevier.com/retrieve/pii/S0165232X03001290

Gagnon RE, Gammon PH. 1995. Triaxial experiments on iceberg and glacier ice. J Glaciol [Internet]. [cited 2015 Apr 30]; 41:528-540. Available from: http://cat.inist.fr/?aModele $=$ afficheN\&cpsidt $=2903987$

Gagnon RE, Wang J. 2012. Numerical simulations of a tanker collision with a bergy bit incorporating hydrodynamics, a validated ice model and damage to the vessel. Cold Reg Sci Technol [Internet]. [cited 2014 Dec 7]; 81:26-35. Available from: http://linkinghub.elsevier.com/retrieve/pii/S0165232X12000870

Gagnon RE. 2011. A numerical model of ice crushing using a foam analogue. Cold Reg Sci Technol [Internet]. [cited 2014 Dec 7]; 65:335-350. Available from: http://linkinghub.elsevier.com/retrieve/pii/S0165232X10002259

Gold LW. 1958. Some observations on the dependence of strain on stress for ice. Can J Phys. 36:1265-1275.

Goodman DJ, Frost HJ, Ashby MF. 1981. The plasticity of polycrystalline ice. Philos Mag A. 43:665-695.

Gürtner A. 2009. Experimental and Numerical Investigations of Ice-Structure Interaction. [place unknown]: Norwegian University of Science and Technology.

Hawkes I, Mellor M. 1972. Deformation and fracture of ice under uniaxial stress. J Glaciol [Internet]. [cited 2015 Apr 30]; 11:103-131. Available from: http://adsabs.harvard.edu/abs/1972JGlac..11..103H

Hilding D, Forsberg J, Gürtner A. 2012. Simulation of Loads from Drifting Ice Sheets on Offshore Structures. In: 12th Int LS-DYNA Conf. [place unknown]; p. 1-8.

Ince ST. 2016. A study on structural crashworthiness due to collision between ships/offshore platforms and ice-ridges, PhD Thesis, Department of Naval Architecture and Ocean Engineering, Pusan National University, Busan, Korea, June.

Johnson GR, Cook WH. 1983. A constitutive model and data for metals subjected to large strains, high strain rates and high temperatures. In: 7th Int Symp Ballist. [place unknown]; p. 541-547.

Jones SJ. 1997. High Strain-Rate Compression Tests on Ice. J Phys Chem B. 101:60996101.

Jones SJ. 2007. A review of the strength of iceberg and other freshwater ice and the effect of temperature. Cold Reg Sci Technol. 47:256-262.

Jones N. 2012. Structural impact. Cambridge University Press, $2^{\text {nd }}$ Edition, New York, USA.

Kim H, Keune JN. 2007. Compressive strength of ice at impact strain rates. J Mater Sci. 42:2802-2806.

Kuehn GA, Schulson EM. 1994. The mechanical properties of saline ice under uniaxial compression. Ann Glaciol [Internet]. [cited 2015 Apr 30]; 19:39-48. Available from: http://adsabs.harvard.edu/abs/1994AnGla..19...39K

Kumar A. 2016. A comparative study of constitutive equations on ice materials, MSc Thesis, Department of Naval Architecture and Ocean Engineering, Pusan National 
University, Busan, Korea, June.

Lachance J, Michel B. 1987. Experimental study of the brittle behaviour of iceberg ice. Proc 9th int conf Port Ocean Eng under Arct Cond POAC [Internet]. [cited 2015 Apr 30]; 87. Available

from: http://scholar.google.com/scholar?q=experimental+study+of+the+brittle+behaviour+of+ iceberg+ice\&btnG $=\& \mathrm{hl}=$ en\&as_sdt $=0 \% 2 \mathrm{C} 5 \# 0$

Lainey L, Tinawi R. 1984. The mechanical properties of sea ice - A compilation of available data. Can J Civ Eng. 11:884-923.

Langleben MP. 1959. Some physical properties of sea ice. II. Can J Phys [Internet]. [cited 2014 Dec 24]; 37:1438-1454. Available from: http://www.nrcresearchpress.com/doi/abs/10.1139/p59-164\#.VJoqT14DcA

Lau M, Lawrence KP, Rothenburg L. 2011. Discrete element analysis of ice loads on ships and structures. Ships Offshore Struct. 6:211-221.

Lau PA, Browne CM. 1989. Bending and compression properties of young sea ice. In: Proc Ocean. Vol. 4. Washington; p. 1292-1297.

Lee RW. 1986. A Procedure for testing cored ice under uniaxial tension. J Glaciol. 32:1985-1986.

Lemaitre J, Desmorat R. 2015. Engineering Damage Mechanics. [place unknown]: Springer Berlin Heidelberg New York Library.

Leppäranta M, Hakala R. 1992. The structure and strength of first-year ice ridges in the Baltic Sea. Cold Reg Sci Technol. 20:295-311.

Liu HW, Miller KJ. 1979. Fracture toughness of fresh-water ice. J Glaciol. 22:135-143.

Liu Z, Amdahl J, Løset S. 2011a. Integrated numerical analysis of an iceberg collision with a foreship structure. Mar Struct [Internet]. [cited 2014 Dec 7]; 24:377-395. Available from: http://linkinghub.elsevier.com/retrieve/pii/S0951833911000475

Liu Z, Amdahl J, Løset S. 2011b. Plasticity based material modelling of ice and its application to ship-iceberg impacts. Cold Reg Sci Technol [Internet]. 65:326-334. Available from: http://dx.doi.org/10.1016/j.coldregions.2010.10.005

Mellor M, Cole DM. 1982. Deformation and failure of ice under constant stress or constant strain-rate. Cold Reg Sci Technol. 5:201-219.

Moslet PO. 2007. Field testing of uniaxial compression strength of columnar sea ice. Cold Reg Sci Technol [Internet]. [cited 2014 Nov 23]; 48:1-14. Available from: http://linkinghub.elsevier.com/retrieve/pii/S0165232X06001303

Mulmule S V, Dempsey JP. 1998. A Viscoelastic Fictitious Crack Model for the Fracture of Sea Ice. Mech Time-Dependent Mater. 1:331-356.

Mulmule SVR, Dempsey JP. 1999. Scale effects on sea ice fracture. Mech Cohesivefrictional Mater. 4:505-524.

Nadreau J, Michel B. 1985. Lois de comportement et de fluage de la glace granulaire simulée de crêtes de pression [Internet]. [place unknown]: Université Laval, Sciences et génie, Génie civil; [cited 2015 Apr 30]. Available from: https://scholar.google.com/scholar?q=Lois+de+comportement+et+de+fluage+de+la+gla ce+granulaire+simul $\sim \mathrm{e}+\mathrm{de}+$ crates $+\mathrm{de}+$ pression $\& b \operatorname{tnG}=\& \mathrm{hl}=\mathrm{en} \& \mathrm{as} \_\mathrm{sdt}=0 \% 2 \mathrm{C} 5 \# 0$ 
Nisja HA. 2014. Numerical Modelling of Brittle Failure in Ice Structures. [place unknown]: Norwegian University of Science and Technology.

Nixon WA, Schulson EM. 1987. a Micromechanical View of the Fracture Toughness of Ice. Le J Phys Colloq. 48:C1-313-C1-319.

Norsok. 2013. N-004 Rev. 3: Design of steel structures. Lysaker, Norway.

Northwood TD. 1947. Sonic determination of the elastic properties of ice. Can J Res [Internet]. [cited 2015 Apr 30]; 25a:88-95. Available from: http://www.nrcresearchpress.com.sci-hub.org/doi/abs/10.1139/cjr47a-011

Ortiz R, Deletombe E, Chuzel-Marmot Y. 2015. Assessment of damage model and strain rate effects on the fragile stress/strain response of ice material. Int J Impact Eng [Internet]. 76:126-138. Available http://linkinghub.elsevier.com/retrieve/pii/S0734743X14002309

from:

Parsons BL, Snellen JB, Hill B. 1987. Preliminary measurements of terminal crack velocity in ice. Cold Reg Sci Technol. 13:233-238.

Pashin VM, Appolonov EM, Belyashov V a., Simonov Y a. 2011. Scientific promotion of $60 \mathrm{MW}$ general-purpose nuclear icebreaker designing. Ships Offshore Struct. 6:185193.

Petrovic JJ. 2003. Review Mechanical properties of ice and snow. J Mater Sci [Internet]. 38:1-6. Available from: http://dx.doi.org/10.1023/A:1021134128038

Saeki H, Nomura T, Ozaki A. 1978. Experimental study on the testing methods of strength and mechanical properties for sea ice. In: IAHR Symp Ice Probl [Internet]. Lulea, Sweden; [cited 2015 Apr 30]. Available from: https://scholar.google.com/scholar?as_sdt=0,5\&q=experimental+study+on+the+testing+ methods+and+strength+and+mechanical+properties+of+sea+ice\&hl=en\#0

Sammonds PR, Murrell SAF, Rist MA. 1998. Fracture of multiyear sea ice. J Geophys Res [Internet]. 103:21795. Available from: http://doi.wiley.com/10.1029/98JC01260

Schulson EM. 1990. The brittle compressive fracture of ice. Acta Metall Mater [Internet]. [cited 2014 Dec 8]; 38:1963-1976. Available from: http://www.sciencedirect.com/science/article/pii/0956715190903084

Schulson EM. 2001. Brittle failure of ice. Eng Fract Mech [Internet]. 68:1839-1887. Available from: http://linkinghub.elsevier.com/retrieve/pii/S0013794401000376

Schwarz J. 1970. The pressure of floating ice-fields on piles. In: Coast Eng Proc [Internet]. Vol. 1. [place unknown]; [cited 2015 Apr 30]. Available from: https://icce-ojstamu.tdl.org/icce/index.php/icce/article/view/2698

Shazly M, Prakash V, Lerch B a. 2009. High strain-rate behavior of ice under uniaxial compression. Int J Solids Struct [Internet]. [cited 2014 Dec 7]; 46:1499-1515. Available from: http://linkinghub.elsevier.com/retrieve/pii/S0020768308004927

Shen L, Zhao S, Lu X, Shi Y. 1988. Effects of temperature and strain rate on uniaxial compressive strength of naturally formed fresh-water ice. In: Proc seventh Int Conf offshore Mech Arct Eng ASME [Internet]. [place unknown]; [cited 2015 Apr 30]; p. 19$23 . \quad$ Available from: https://scholar.google.com/scholar?q=Effects+of+temperature+and+strain+rate+on+uni axial+compressive+strength+of+naturally+formed+fresh- 
water $+\mathrm{ice} \& \mathrm{btnG}=\& \mathrm{hl}=\mathrm{en} \& \mathrm{as} \_\mathrm{sdt}=0 \% 2 \mathrm{C} 5 \# 0$

Shepard ML, Goldston CS, Cocks FH. 1976. The H2O-NaCl-glycerol phase diagram and its application in cryobiology. Cryobiology. 13:9-23.

Sinha NK, Timco GW, Frederking RMW. 1987. Recent advances in ice mechanics in Canada. Appl Mech Rev. 40:1214.

Sinha NK. 1984. Uniaxial compressive strength of first-year and multi-year sea ice. Can J Civ Eng. 11:82-91.

Tabata T. 1967. Studies of the mechanical properties of sea ice. In: Phys Snow Ice Proc [Internet]. [place unknown]: Hokkaido University; p. 481-497. Available from: http://hdl.handle.net/2115/20320

Timco G., Frederking RM. 1984. An investigation of the failure envelope of granular/discontinuous-columnar sea ice. Cold Reg Sci Technol [Internet]. [cited 2015 $\begin{array}{llll}\text { Apr 30]; } & 9: 17-27 . & \text { Available }\end{array}$ http://www.sciencedirect.com/science/article/pii/0165232X84900442

Timco GW, Frederking RMW. 1996. A review of sea ice density. Cold Reg Sci Technol. $24: 1-6$

Timco GW, O'Brien S. 1994. Flexural strength equation for sea ice. Cold Reg Sci Technol. 22:285-298.

Tvergaard V, Hutchinson JW. 1992. The relation between crack growth resistance and fracture process parameters in elastic-plastic solids. J Mech Phys Solids [Internet]. 40:1377-1397. Available

from: http://linkinghub.elsevier.com/retrieve/pii/0022509692900203

Urabe N, Inoue M. 1988. Mechanical Properties of Antarctic Sea Ice. J Offshore Mech Arct Eng. 110:403.

Urabe N, Iwasaki T, Yoshitake A. 1980. Fracture toughness of sea ice. Cold Reg Sci Technol. 3:29-37.

Vaudrey K. 1977. Ice engineering: study of related properties of floating sea-ice sheets and summary of elastic and viscoelastic analyses. Port Hueneme, CA, Naval. Civ Eng Lab Rep R860) [Internet]. [cited 2015 Apr 30]. Available from: https://scholar.google.com/scholar?q=Ice+Engineering--+Study+of+Related+Prop+erties+of+Floating+Sea+Ice+Sheets+and+Summary+of+Elastic+and+Viscoelastic+An alyses $\& b t n G=\& h l=e n \& a s \_s d t=0 \% 2 \mathrm{C} 5 \# 1$

Williams KL. 1992. Sea ice elastic moduli: Determination of Biot parameters using infield velocity measurements. J Acoust Soc Am. 91:2627.

Zamankhan P. 2010. Simulations of collision of ice particles. Commun Nonlinear Sci Numer Simul [Internet]. [cited 2014 Dec 7]; 15:1538-1552. Available from: http://linkinghub.elsevier.com/retrieve/pii/S1007570409003700

Zong R. 2012. Finite element analysis of ship-ice collision using Ls-Dyna. Newfoundland: Memorial university of Newfoundland. 